\title{
Understanding the Equatorial Pacific Cold Tongue Time-Mean Heat Budget. Part I: Diagnostic Framework
}

\author{
SULAGNA RAY \\ Atmospheric and Oceanic Sciences Program, Princeton University, Princeton, New Jersey \\ Andrew T. WitTenberg, Stephen M. Griffies, And FAnRong ZENG \\ National Oceanic and Atmospheric Administration/Geophysical Fluid Dynamics Laboratory, Princeton, New Jersey
}

(Manuscript received 14 March 2018, in final form 1 August 2018)

\begin{abstract}
The Pacific equatorial cold tongue plays a leading role in Earth's strongest and most predictable climate signals. To illuminate the processes governing cold tongue temperatures, the upper-ocean heat budget is explored using the GFDL-FLOR coupled GCM (the forecast-oriented low ocean resolution version of CM2.5). Starting from the exact temperature budget for layers of time-varying thickness, the layer temperature tendency terms are studied using hourly-, daily-, and monthly-mean output from a 30-yr simulation driven by present-day radiative forcings. The budget is then applied to 1) a surface mixed layer whose temperature is highly correlated with SST, in which the air-sea heat flux is balanced mainly by downward diffusion of heat across the layer base, and 2) a thicker advective layer that subsumes most of the vertical mixing, in which the air-sea heat flux is balanced mainly by monthly-scale advection. The surface warming from shortwave fluxes and submonthly meridional advection and the subsurface cooling from monthly vertical advection are both shown to be essential to maintain the cold tongue thermal stratification against the destratifying effects of vertical mixing. Although layer undulations strongly mediate the tendency terms on diurnal-to-interannual scales, the 30-yr-mean tendencies are found to be well summarized by analogous budgets developed for stationary but spatially varying layers. The results are used to derive practical simplifications of the exact budget, to support the analyses in Part II of this paper, and to facilitate broader application of heat budget analyses when evaluating and comparing climate simulations.
\end{abstract}

\section{Introduction}

The Pacific equatorial cold tongue (ECT) is a key region for El Niño-Southern Oscillation (ENSO). Sea surface temperature (SST) variations in the ECT affect the westward and poleward SST gradients over the tropical Pacific, which in turn lead to zonal $(x)$ and meridional $(y)$ shifts of atmospheric convection (Capotondi et al. 2015; Choi et al. 2015). Past and future changes in ECT SST and ECT biases in model simulations have both been shown to strongly affect simulations of global climate and variability including ENSO (Wittenberg 2002; Vecchi and Wittenberg 2010; Collins et al. 2010;

\footnotetext{
${ }^{a}$ Current affiliation: Department of Marine Sciences, University of Connecticut, Groton, Connecticut.
}

Corresponding author: Sulagna Ray, sulagna.ray@gmail.com
Wittenberg 2015; Graham et al. 2017; Chen et al. 2017; Timmermann et al. 2018).

The tropical Pacific upper ocean represents a vast heat reservoir that plays a central role in tropical climate variations. Within the top few tens of meters of the tropical Pacific Ocean, intermittent stirring and mixing - arising from wave-, Langmuir-, and shear-driven turbulence, and convective instabilities - act to vertically homogenize the ocean temperature, salinity, and density within a surface mixed layer (SML). Understanding the spatial and temporal variations of SML temperature is critical to improving simulations of the tropical Pacific climatology and ENSO.

Previous work has used diverse definitions for the SML, including the depth where the ocean temperature is $0.5 \mathrm{~K}$ (Levitus 1982; McPhaden 2002), 0.8 K (Kara et al. 2000), or $1 \mathrm{~K}$ (Swenson and Hansen 1999) below the local SST, or the depth where the potential density $(\sigma)$ is $0.03 \mathrm{~kg} \mathrm{~m}^{-3}$ (de Boyer Montégut et al. 2004) or $0.125 \mathrm{~kg} \mathrm{~m}^{-3}$ (Levitus 1982; Huang et al. 2010) denser than at the surface. These 
choices do not always coincide; for example, in the west Pacific warm pool, intense rainfall can produce a surface fresh pool with a sharp and shallow halocline, leading to a separation (barrier layer) between the pycnocline and a deeper thermocline.

Near the equator, the SML depth exhibits pronounced zonal variations (due to the zonal thermocline tilt, and the halocline in the west Pacific), and large temporal fluctuations (due to the diurnal cycle, seasonal cycle, and ENSO). When examining the SML temperature budget, many studies have used SMLs with depths that are constant in both space and time (e.g., Zebiak and Cane 1987; Zheng et al. 2010; DiNezio et al. 2012; DiNezio and Deser 2014), which may be acceptable for some limited regions or regimes but not others. In this study we apply the method of Kim et al. (2006, hereafter K06), who provided an exact formulation for the temperature budget of a spatially and temporally varying SML. We then systematically examine approximations of that method, both to simplify future analysis and to connect to previous studies that have used simpler methods.

Part I of this two-part paper derives a diagnostic temperature budget framework to help illuminate the oceanic contributors to the time-mean ECT intensity. The framework is developed using detailed diagnostic output from the GFDL-FLOR coupled GCM (the forecast-oriented low ocean resolution version of CM2.5), which produces a particularly realistic simulation of the equatorial Pacific cold tongue climatology. We define the SML depth using the potential density difference $(\Delta \sigma)$ from the surface, and explore the utility of various $\Delta \sigma$ criteria for understanding the climatology and variability of SST, particularly in the Pacific ECT region. Part II (Ray et al. 2018, hereafter Part II) then leverages the framework via further application to FLOR and observational ocean reanalyses, as well as to a fluxadjusted version of FLOR with corrected climatological SSTs and wind stress. It is hoped that this diagnostic heat budget framework and its applications will stimulate further analysis of the equatorial oceanic heat budget, both to interpret the GCM simulations contributed to the upcoming phase 6 of the Coupled Model Intercomparison Project (CMIP6; Eyring et al. 2016) and to help guide the redesign of the Tropical Pacific Observing System (TPOS2020; Cravatte et al. 2016).

\section{Datasets}

\section{a. Observations and reanalyses}

For surface observations, we use SST from HadISST.v1 (Rayner et al. 2003), surface heat fluxes from TropFlux.v1 (Praveen Kumar et al. 2012), and surface wind stress from
ERA-Interim (Dee et al. 2011). Subsurface temperature and currents are from the SODA 2.2.4 ocean reanalysis (Giese and Ray 2011), in which an ocean model forced by winds from the Twentieth Century Reanalysis (Compo et al. 2011) assimilates all available temperature and salinity profiles. The ocean model in SODA 2.2.4 is based on POP version 2.0.1 numerics (Smith et al. 1992), with a horizontal grid spacing of roughly $0.4^{\circ}$ longitude and $0.25^{\circ}$ latitude, 40 vertical levels, a $K$-profile parameterization for vertical mixing (Large et al. 1994), and a biharmonic horizontal mixing scheme. The assimilation is carried out sequentially using a 10-day cycle, and outputs are averaged every 5 days and mapped onto a uniform $0.5^{\circ} \times 0.5^{\circ}$ global grid (Giese and Ray 2011). All observations and reanalysis products used for this study span the period 1980-2010.

\section{b. FLOR coupled GCM}

The FLOR global coupled GCM is described by Vecchi et al. (2014) and Wittenberg et al. (2018). Compared to its predecessor model (CM2.1), FLOR has shown remarkable improvement in its simulation of tropical Pacific climate (Wittenberg et al. 2018). FLOR's atmosphere and land components have a horizontal grid spacing of roughly $50 \mathrm{~km}$. The atmospheric component has a finite-volume dynamical core, implemented on a cubed-sphere grid. The ocean component is based on MOM5 code (Griffies 2012), with a horizontal grid spacing of $1^{\circ} \times 1^{\circ}$, telescoping to $0.33^{\circ}$ meridional spacing near the equator. The ocean has 50 vertical layers, with a grid spacing of about $10 \mathrm{~m}$ over the top $270 \mathrm{~m}$ (Wittenberg et al. 2006). FLOR's ocean component uses a $z^{*}$ vertical coordinate, so that all cells in the column stretch when the sea surface is elevated, and compress when the sea surface is depressed.

To produce the control run, FLOR is integrated for 300 years with fixed 1990 values of atmospheric composition, solar forcings, and land cover. Monthly- and annual-mean diagnostics, including the full set of heat budget terms diagnosed by the ocean model, are saved throughout these simulations. During the 30-yr epoch from years 21 to 50, daily-mean ocean diagnostics are saved as well. We also discuss results from a run of the same model but with historical interannually varying radiative forcings (natural and anthropogenic), for which we saved ocean diagnostics at every time step (hourly) for one full year (1979).

Figure $1 \mathrm{~b}$ shows the SST and surface wind stress biases in the FLOR control simulation. FLOR exhibits a slight cold bias in the eastern equatorial Pacific cold tongue, a cold bias poleward of $10^{\circ}$ latitude in both hemispheres (mainly in the western Pacific), and warm biases in the off-equatorial central Pacific and near the coast of South 
Mean SST and wind stress

(a) Observed

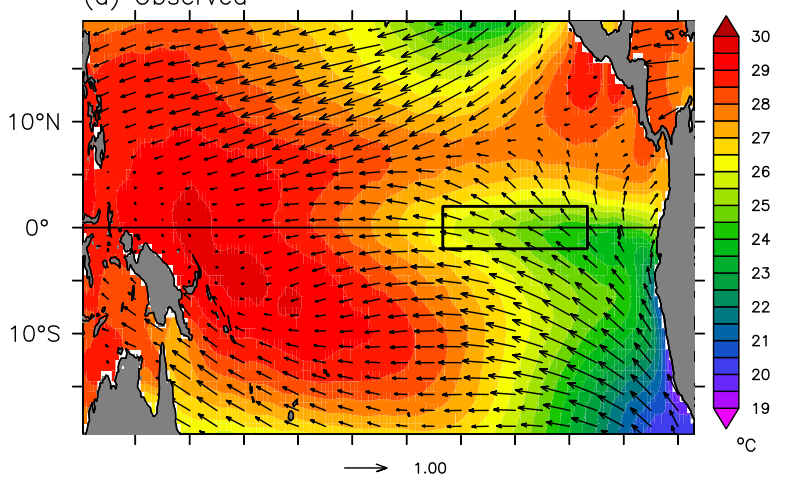

(b) Bias in FLOR

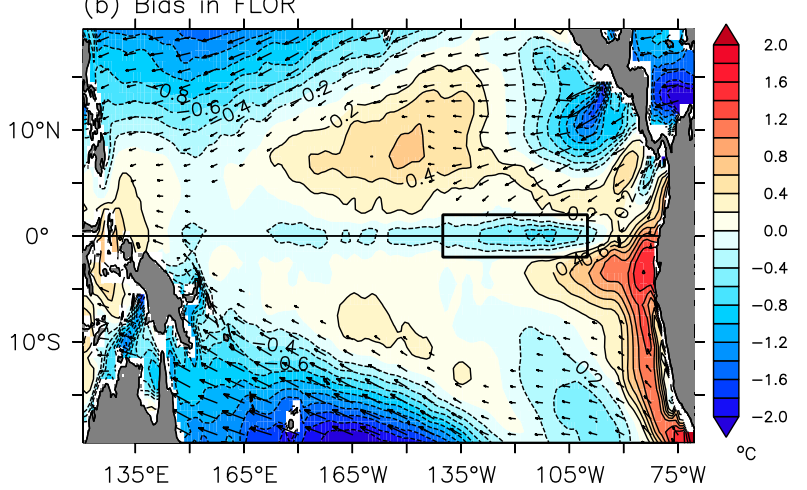

FIG. 1. (a) Mean SST (shading) from HadISST observations (1981-2010) overlaid by mean surface wind stress (dPa) (vectors) from ERA-Interim (1981-2010), with westward vectors indicating westward stress on the ocean. (b) Biases from 100-yr FLOR control simulation relative to observations in (a). Only wind stress biases exceeding $0.1 \mathrm{dPa}$ are shown in (b). Black box indicates the ECT region $\left(2^{\circ} \mathrm{S}-2^{\circ} \mathrm{N}, 140^{\circ}-100^{\circ} \mathrm{W}\right)$.

America. FLOR also shows overly strong easterly trade winds in the off-equatorial west Pacific. These and other aspects of the FLOR simulation of the tropical Pacific climatology are discussed in more detail by Wittenberg et al. (2018).

\section{Volume-mean temperature budget for an evolving domain}

\section{a. Motivation}

SML temperature budgets, which analyze flows of heat into and out of the SML for a given region, are powerful diagnostics of the sources of SST biases in an ocean model. Many studies have demonstrated the utility of these budgets for determining the dominant mechanisms of heat transport within the tropical Pacific, and for understanding the causes of SSTA growth and decay on seasonal to interannual time scales (Vialard et al. 2001; McPhaden 2002; Wittenberg 2002; Kim et al.
2007; Huang et al. 2010, 2012; DiNezio et al. 2012; Boucharel et al. 2015; Huang et al. 2010, 2012; Graham et al. 2017). However, most previous studies have used approximations and ad hoc assumptions in formulating the budgets, and did not demonstrate quantitative closure.

An exception is the study of K06, who computed all budget terms exactly, including the temperature tendency due to entrainment and detrainment associated with temporal variations in SML depth. Following Lee et al. (2004), K06 formulated the total advective temperature tendency of a given reference volume in terms of an integral of advective fluxes of "relative temperature" $T_{\text {rel }}=T-\langle T\rangle$ over the bounding surface of the volume, where $T$ is the temperature on the bounding surface and $\langle T\rangle$ is the volume-mean temperature. This surface integral directly measures the directional warming/cooling due to external influences at each face of the volume, in contrast to an advective-form volume integral that also includes internal redistributions of temperature within the volume. The two forms yield the same total advective tendency, but their directional decomposition and interpretation are different (Lee et al. 2004).

If the reference volume varies in time, then one must also account for the change in temperature due to the newly included (entrained) or excluded (detrained) water. If for example the SML depth is defined using $\Delta \sigma$, then a surface heating (e.g., due to solar radiation during the day) will by definition shoal the layer, even if there is no temperature change at depth. This shoaling will then exclude some relatively cold water at the SML base, yielding a net warming effect from detrainment. Conversely, a surface cooling (e.g., due to longwave radiation at night) will cause the layer to deepen, leading to inclusion of new relatively cold water at the base of the layer, yielding a net cooling effect from entrainment. K06 close the temperature budget by evaluating the temperature tendency due to entrainment/detrainment exactly, using the SML depth change and the relative temperature of the entrained or detrained water $(\Delta T)$. This is in contrast to prior ad hoc approximations of $\Delta T$ that did not explicitly close the temperature budget, such as using temperatures from a sublayer below the SML (Alexander et al. 2000), using temperatures at a fixed depth below the base of the SML, such as $20 \mathrm{~m}$ (McPhaden 2002) or $10 \mathrm{~m}(\mathrm{Qu} 2003)$, or using a constant temperature for $\Delta T$ such as $1^{\circ} \mathrm{C}$ (Qiu and Kelly 1993) or $0.75^{\circ} \mathrm{C}$ (Swenson and Hansen 1999).

Here we adopt the budget formulation of K06, using their formulation for entrainment/detrainment and fluxform advection of relative temperatures. After demonstrating closure of the volume temperature budget in 
FLOR, we then pursue some practical approximations in section 4 to permit wider application of these methods to a broader range of climate datasets.

\section{b. Formulation}

Following Lee et al. (2004) and K06, the temperature tendency for a Boussinesq ocean model (such as FLOR's ocean component) is

$\partial_{t} T=\frac{\partial_{z} q}{\rho_{0} C_{p}}-\nabla \cdot(\mathbf{u} T)+$ vertical mixing + other,

where $\partial_{i}$ indicates a partial derivative in the $I$ direction, $\nabla=\left(\partial_{x}, \partial_{y}, \partial_{z}\right), T$ is the grid-cell-mean temperature, $z$ is upward, $\partial_{z} q$ is the vertical convergence of heat flux associated with air-sea exchange and penetrative shortwave radiation, $\rho_{0}=1035 \mathrm{~kg} \mathrm{~m}^{-3}$ is a constant seawater reference potential density, $C_{p} \approx 3992 \mathrm{~J} \mathrm{~kg}^{-1} \mathrm{~K}^{-1}$ is the specific heat capacity of seawater, $\mathbf{u}=(u, v, w)$ is the three-dimensional current velocity, "vertical mixing" denotes the temperature tendency due to the parameterized vertically local component of subgrid-scale turbulent vertical mixing in the ocean model, and "other" denotes additional processes (e.g., subgrid-scale lateral mixing, nonlocal vertical mixing, sub-mesoscale mixing, and sensible heating due to rainfall and rivers) that in the ocean model play a relatively minor role in the temperature budget of the tropical Pacific upper-ocean domains that we examine here.

Consider a three-dimensional domain $D$, extending over a horizontal region $R$ with purely vertical $x$ and $y$ boundaries, and extending from the surface to a depth $h$ that varies spatially within the domain. A volumeaverage over $D$ of (1) gives

$$
\begin{aligned}
\partial_{t} T_{D}= & \frac{Q_{\mathrm{sfc}}-Q_{\mathrm{pen}}}{\rho_{0} C_{p} V_{D}}+\langle\text { advection }\rangle+\langle\text { vertical mixing }\rangle \\
& +\langle\text { detrainment }\rangle+\langle\text { other }\rangle
\end{aligned}
$$

where \langle\rangle denotes a volume average over $D, T_{D}=\langle T\rangle$, $Q_{\text {sfc }}$ is the (positive downward) horizontally averaged net surface heat flux, $Q_{\text {pen }}$ is the (positive downward) horizontally averaged penetrative solar flux at the layer base, and $V_{D}$ is the volume of $D$.

Applying the divergence theorem and volume conservation (incompressibility), the volume-averaged advective temperature tendency is

$$
\langle\text { advection }\rangle=-\frac{1}{V_{D}} \int_{S_{D}}(\mathbf{u} \cdot \mathbf{n})\left(T-T_{D}\right) d S,
$$

where $S_{D}$ is the bounding surface of $D, \mathbf{n}$ is the outward unit normal vector along $S_{D}$, and $T-T_{D}$ is the temperature anomaly at the boundary relative to the domain average (Lee et al. 2004).

For the near-equatorial mixed layer budgets that are the main focus of this paper, we find that nearly all of the simulated temperature tendency arising from vertical mixing is produced by the local term $-\kappa_{z} \partial_{z} T$, where $\kappa_{z}$ is the local instantaneous vertical diffusivity. Nonlocal mixing plays a very minor role in the temperature budget, and we have grouped it together with other weak terms into the small residual "other" term in (2). The temperature tendency due to mixing is then the vertical convergence of the local heat flux, $-\partial_{z}\left(-\kappa_{z} \partial_{z} T\right)=\partial_{z}\left(\kappa_{z} \partial_{z} T\right)$, which averaged over the full volume $D$ gives

$$
\begin{aligned}
\langle\text { vertical mixing }\rangle & =\left\langle\partial_{z}\left(\kappa_{z} \partial_{z} T\right)\right\rangle \\
& =-\frac{1}{V_{D}} \iint_{S_{-h}} \kappa_{z} \partial_{z} T d x d y,
\end{aligned}
$$

where $\iint_{S_{-h}}$ denotes integration along the layer base. Generally, the domain $D$ will tend to cool due to vertical mixing, via a downward heat flux through the base of the layer.

Appendix A describes the detrainment term in (2), which is only present if the layer thickness evolves in time.

\section{c. Layer depth notation}

Here we define $h$ as the depth at which $\sigma$ (the potential density referenced to the surface) reaches a critical difference $\Delta \sigma_{\text {crit }}$ from the local surface value $\sigma(z=0)$. Section 4 examines the dependence of $h$ on the timeaveraging of the density field, as well as the dependence of the SML temperature budget on the choice of $h$; these will ultimately motivate a simplified two-layer approach to the ECT temperature budget.

We shall denote a particular choice of $h$ using a shorthand, expressed as $H_{\Delta \sigma_{\text {crit }} \tau}$. The subscript $\tau$ is a letter indicating the time averaging applied to the $T$ and $S$ fields, before computing $\sigma$ and $h$ : hourly mean ("h"), daily mean ("d"), monthly mean ("m"), 12-month climatological cycle of monthly means ("c"), temporally stationary climatological annual mean ("a"), or a simple temporally stationary and spatially fixed depth ("f"). For example, $H_{0.125 \mathrm{~m}}$ denotes $\Delta \sigma_{\text {crit }}=0.125 \mathrm{~kg} \mathrm{~m}^{-3}$ applied to the evolving monthly means of $T$ and $S$. In contrast, $H_{0.3 \mathrm{a}}$ denotes $\Delta \sigma_{\text {crit }}=0.3 \mathrm{~kg} \mathrm{~m}^{-3}$ applied to the stationary climatological annual means of $T$ and $S$. We use a similar notation to denote the vertically averaged temperature of a layer: for instance, $T_{0.3 \mathrm{a}}$ denotes the vertical-mean temperature of a surface layer with its base at $H_{0.3 a}$.

There are two competing considerations in selecting an SML depth for analysis. First, the SML should be thin enough that its vertical-mean temperature resembles the SST, and the SML temperature budget directly 
illuminates the processes affecting the SST; we thus require the monthly-mean SML temperature to be highly correlated with monthly-mean SST. Second, it is desirable for the SML to be sufficiently thick that it absorbs most of the sunlight entering from the surface, and is less impacted by the strong diurnal cycle of insolation and vertical mixing near the surface, which can obscure the slower deep advective processes that are more relevant to ENSO (Brainerd and Gregg 1995; de Boyer Montégut et al. 2004). The analysis that follows will point to $H_{0.125 \mathrm{~m}}$ as an excellent fit to both of these criteria, with $H_{0.2 \mathrm{c}}$ and $H_{0.3 \mathrm{a}}$ providing reasonable approximations. For example, for all three definitions the correlation between the FLOR-simulated SST and SML temperature exceeds 0.99 , for both monthly means and running annual means, and for either a single ECT column $\left(0^{\circ} \mathrm{N}, 125^{\circ} \mathrm{W}\right)$ or volume-averaging over the ECT box $\left(2^{\circ} \mathrm{S}-2^{\circ} \mathrm{N}, 140^{\circ}-100^{\circ} \mathrm{W}\right)$. We will therefore focus on these particular SML definitions in what follows.

\section{d. Focus region}

We shall focus mainly on the ECT region $\left(2^{\circ} \mathrm{S}-2^{\circ} \mathrm{N}\right.$, $140^{\circ}-100^{\circ} \mathrm{W}$ ) indicated in Fig. 1. This is the location of FLOR's strongest cold bias along the equator and also a key region for seasonal and ENSO SST variations in the model and real world. This region $R$ and its time-varying thickness $h$ define the domain $D$, whose temperature $T_{D}$ is driven by fluxes of temperature across its six faces (west, east, south, north, bottom, top). These fluxes will generally be grouped into the three directions $x, y$, and $z$. An exception is the horizontal advective flux crossing the sloped bottom face (referred to as "lateral induction" by K06), which will generally be grouped together with the vertical advective flux at the bottom face to constitute the total inward flux across the bottom face.

\section{e. Diurnal budget for the surface layer}

To illustrate the diurnal variations of the local depth and temperature of the SML in the cold tongue region, Fig. 2a shows the evolution of the full diurnally varying temperature budget of $H_{0.125 \mathrm{~h}}$ as simulated by FLOR, on the equator at $125^{\circ} \mathrm{W}$ during a particular 24-day period in boreal autumn. Each morning as the sun rises, the SML warms (black line) and shoals (orange line) due to increasing solar radiation (red line). This shoaling drives further warming of the SML from detrainment (light blue line), as relatively cold water is excluded at the base of the SML. The enhanced stratification of the daytime SML also weakens the cooling from diffusive vertical mixing (green line). In the evening as the sun sets, sustained cooling from evaporation and longwave emission redeepens the SML, resulting in entrainment cooling as the deepening SML annexes relatively cold water at the SML base. The reduced stratification at night also enhances and deepens the vertical mixing, providing another cooling effect.

The diurnal cycle of SML temperature is strongest where the SML is shallow (e.g., in the ECT), since a shallower SML responds more strongly to surface fluxes and entrainment/detrainment. Compared to the surface heat flux and entrainment terms, the diurnal cycles of mixing and advection are relatively weak in the ECT SML. However, the advection does vary strongly at time scales of 20 days or more, especially during August-September when tropical instability waves (TIWs) are particularly active.

When the SML depth $h$ is held temporally fixed at $H_{0.3 a}$ (Fig. 2c), the layer entrainment term vanishes by definition. The SML temperature also shows weaker diurnal variations, as $H_{0.3 \mathrm{a}}$ removes the flux-amplifying and vertical diffusion-attenuating effects of a thin daytime $h$. However, at time scales longer than a day, the SML budget and relative balance of terms for the static SML ( $H_{0.3 a}$; Fig. 2 d) closely resemble those for the fully varying SML $\left(H_{0.125 \mathrm{~h}}\right.$; Fig. $\left.2 \mathrm{~b}\right)$.

\section{f. Monthly budget for the ECT surface layer}

Figure 3a shows the long-term evolution of FLOR's temperature budget, for the volume bounded by the ECT region and $H_{0.125 \mathrm{~m}}$ during years $21-50$ of the simulation. Within the ECT, the month-to-month fluctuations of $H_{0.125 \mathrm{~m}}$ are larger than the subdiurnal fluctuations of $H_{0.125 \mathrm{~h}}$ in Fig. 2a. The monthly-mean $H_{0.125 \mathrm{~m}}$ exhibits a prominent seasonal cycle (thin in MAM, thick in SON) and can also thin to $15 \mathrm{~m}$ during La Niña and thicken to $80 \mathrm{~m}$ before El Niño (Fig. 3a, orange curve, right axis). Of the monthly-mean budget terms, vertical diffusion is the strongest, with peak cooling occurring when the SML is thin. This diffusive cooling and its variations are partly offset by the surface heat flux, so that the net temperature tendency can also be influenced by variations in advection-namely, strong advective cooling during La Niña (when the SML is thin and diffusive cooling is also strong), and weaker advective cooling during El Niño (when the SML is thick and diffusive cooling is also weak). At monthly time scales the advective tendency is skewed, with cooling events being more extreme than warming events, although advection can occasionally serve as a weak absolute warming term during El Niño. The residual sum of all other terms (gray dashed line) consists mainly of high-frequency monthly variations, which contribute very little to the running annual mean (Fig. 3b).

Figure $3 \mathrm{c}$ shows the monthly budget analysis for a stationary SML of depth $H_{0.3 a}$. For this stationary layer the advective term becomes relatively more importantespecially during La Niña, when $H_{0.3 a}$ is deeper than a time-varying SML, which boosts the advective cooling but tempers the vertical diffusive cooling. For $H_{0.3 \mathrm{a}}$ the 
(a) Hourly means for $\mathrm{H}_{0.125 \mathrm{~h}}$

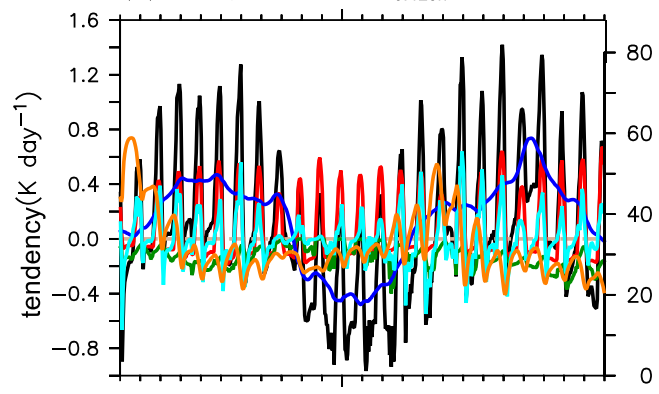

(c) Hourly means for $\mathrm{H}_{0.3 a}$

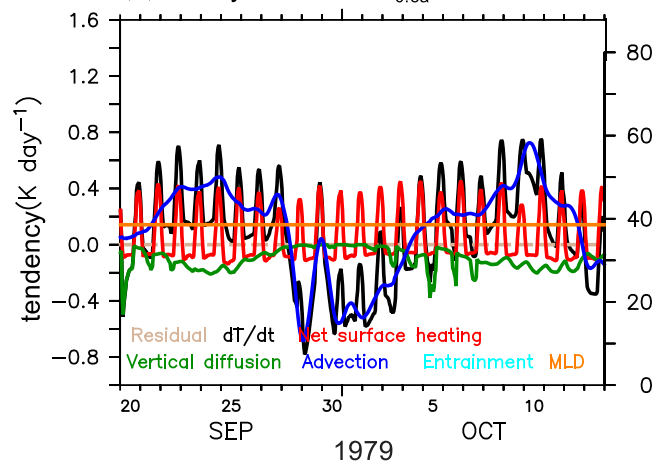

(b) Daily means for $\mathrm{H}_{0.125 \mathrm{~h}}$

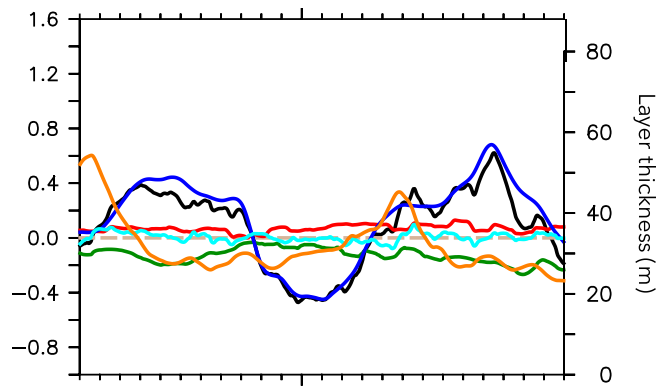

(d) Daily means for $\mathrm{H}_{0.3 \mathrm{a}}$

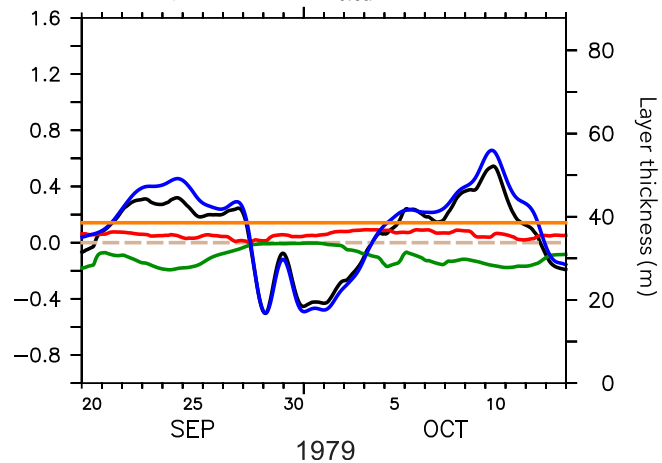

FIG. 2. Surface mixed layer (SML) temperature tendencies $\left(\mathrm{K} \mathrm{day}^{-1}\right)$ during a boreal autumn period with strong TIW activity from the FLOR run with historical radiative forcings, for a single ocean model column at $125^{\circ} \mathrm{W}$ on the equator, and an SML with depth $h$ equal to (a) $H_{0.125 \mathrm{~h}}$ and (c) $H_{0.3 \mathrm{a}}$ (hourly means). (b),(d) As in (a),(c), but a running daily mean is applied after computation of the curves in (a) and (c). $H_{\Delta \sigma_{\text {cit }}}$ indicates a density criterion of $\Delta \sigma_{\text {crit }} \mathrm{kg} \mathrm{m}^{-3}$ applied to the timeaveraged $T$ and $S$ fields, with the averaging interval $\tau$ indicated as hourly (" $h$ ") or annual-mean climatological ("a"). Shown are the SML depth ( $h$, orange, right axis), total temperature tendency (diagnosed directly from the simulated temperature change, black, left axis), net surface heat flux minus solar penetration through the SML base (red), vertical diffusion (green), total advection (blue), and entrainment (light blue). The residual temperature tendency (gray) is extremely small, and consists of the total tendency minus all the other terms shown. The strong periodic signal in (a) and (c) is the diurnal cycle.

advection thus becomes even more skewed toward cooling than for $H_{0.125 \mathrm{~m}}$.

Running annual means (Figs. 3b,d) highlight the differences between the budgets for $H_{0.125 \mathrm{~m}}$ and $H_{0.3 \mathrm{a}}$ : the budget for the stationary $H_{0.3 \mathrm{a}}$ is less dominated by the interplay of surface heating and vertical diffusive cooling, especially during La Niña when $H_{0.125 \mathrm{~m}}$ is shallow. At annual time scales advection acts almost exclusively as a cooling term. Interannual variations of $\partial_{t} T_{0.3 \mathrm{a}}$ are largely driven by the variations in advective cooling, with the variations in net surface heat flux partially offset by variations in vertical diffusive cooling.

\section{Practical simplifications of the temperature budget}

\section{a. Motivation}

It can be problematic to interpret the time-mean temperature budget of a layer of fluctuating thickness, since the budget refers to greater volumes and thermal capacities when the layer is thick than when it is thin. In addition, the full temperature budget of section 3 , in particular the detrainment term (A2), often cannot be evaluated for existing output from climate simulations, such as the CMIP5 simulations or existing ocean reanalyses. This is because ocean model fields in climate simulations are typically saved as time averages (e.g., daily or monthly), so that the spatial domain $D$, local temperature $T$, and domain-averaged temperature $T_{D}$ are not known at the start and end of the averaging interval [times $t \pm(\Delta t / 2)$ ]. While these quantities can be interpolated from the time-averaged fields, doing so introduces error in the detrainment term as demonstrated in section $4 \mathrm{c}$.

In contrast, a temperature budget for a stationary layer ( $h$ and $D$ fixed in time) can be easier to interpret and apply: it always refers to the same volume and same model grid cells, and it is easier to close since the 

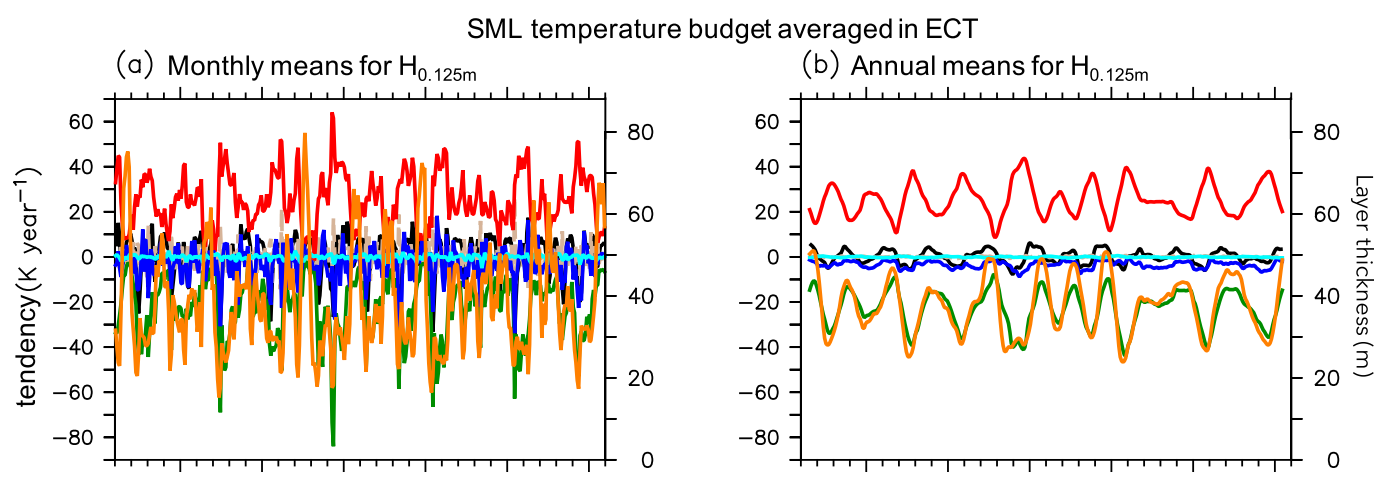

(c) Monthly means for $\mathrm{H}_{0.3 a}$

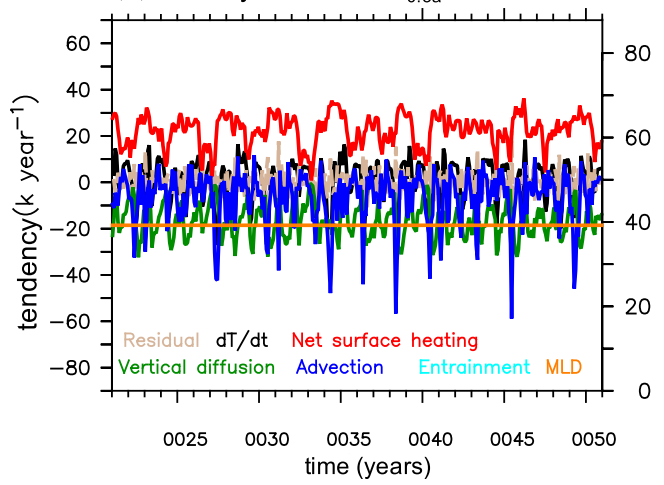

(d) Annual means for $\mathrm{H}_{0.3 \mathrm{a}}$

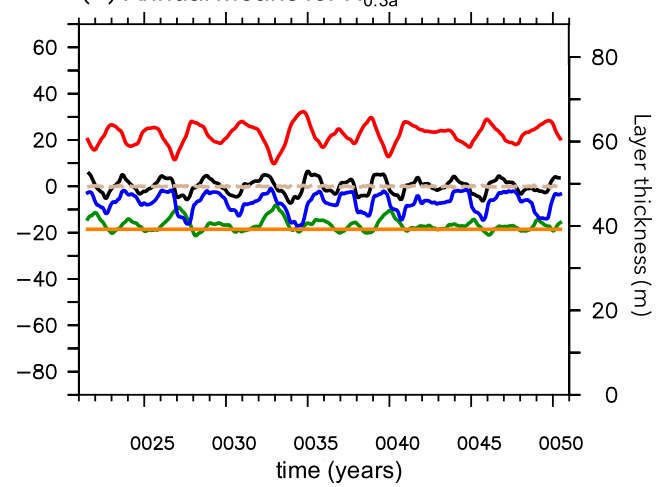

FIG. 3. (a),(c) As in Fig. 2, but for simulated monthly-mean tendencies of SML temperature averaged over the cold tongue box $\left(2^{\circ} \mathrm{S}-2^{\circ} \mathrm{N}, 140^{\circ}-100^{\circ} \mathrm{W}\right)$, during years $21-50$ of the FLOR control run. (b), (d) As in (a), (c), but with a running annual mean applied after computation of the curves in (a) and (c).

detrainment term vanishes. One concern, however, is that the climatological budget for a stationary layer may be less representative of the "average" composition of processes relevant to SST variations. In this section, we examine the extent to which a stationary- $h$ budget can substitute for a varying- $h$ budget in the ECT region.

Climate simulations and ocean reanalyses usually do not include time-averaged advective products (3) and mixing terms (4) as part of their standard output. To facilitate analysis of existing and future model datasets, it is therefore useful to consider what budget information can be gleaned from commonly saved fields, such as monthly-mean $T, S$, and $\mathbf{u}$. This motivates our development in section $4 \mathrm{~d}$ of a two-layer area-averaged approach to the climatological temperature budget of the ECT.

\section{b. Layer depths from time-averaged fields}

Figure 4 shows the near-equatorial time-mean SML depths, computed using various density criteria applied to monthly-mean $T$ and $S$ from the SODA 2.2.4 reanalysis and the FLOR simulation. This figure illustrates the spatial variation of the SML depth along the equator, and shows that the time-mean $\bar{H}_{0.125 \mathrm{~m}}$ is generally well approximated by both $\bar{H}_{0.2 \mathrm{c}}$ and $\bar{H}_{0.3 \mathrm{a}}$ within the ECT.

In SODA $\bar{H}_{0.125 \mathrm{~m}}$ is thickest near $165^{\circ} \mathrm{W}$ and thinnest in the far eastern and far western Pacific. Within the ECT box, SODA's average $\bar{H}_{0.125 \mathrm{~m}}$ is about $30 \mathrm{~m}$. FLOR qualitatively captures these features, although its $\bar{H}_{0.125 \mathrm{~m}}$ is about $10 \mathrm{~m}$ deeper than in SODA. Within the ECT, FLOR's $\bar{H}_{0.125 \mathrm{~m}}$ ranges from $15 \mathrm{~m}$ on the equator in the east to $60 \mathrm{~m}$ near $2^{\circ} \mathrm{S}$ in the central Pacific. Averaged over the ECT, FLOR's $H_{0.125 \mathrm{~m}}$ varies seasonally from $26 \mathrm{~m}$ in April to $46 \mathrm{~m}$ in July, and interannually from only $5 \mathrm{~m}$ during La Niña to over $90 \mathrm{~m}$ during El Niño.

The distribution of SML depth is positively skewed, with long periods of shallow $h$ (La Niña or neutral conditions) punctuated by brief but very deep $h$ (El Niño). As a result, the $h$ diagnosed from temporally averaged density profiles is generally shallower than the time-mean of $h$ diagnosed from local and instantaneous density profiles. Figure 4 illustrates that to approximate FLOR's time-mean depth of monthly-varying $H_{0.125 \mathrm{~m}}$ in the tropical Pacific and ECT regions, one must apply a larger potential density difference criterion of $H_{0.2 \mathrm{c}}$ when using the seasonally varying climatological $T$ and $S$, or an even larger criterion $H_{0.3 \mathrm{a}}$ when using 


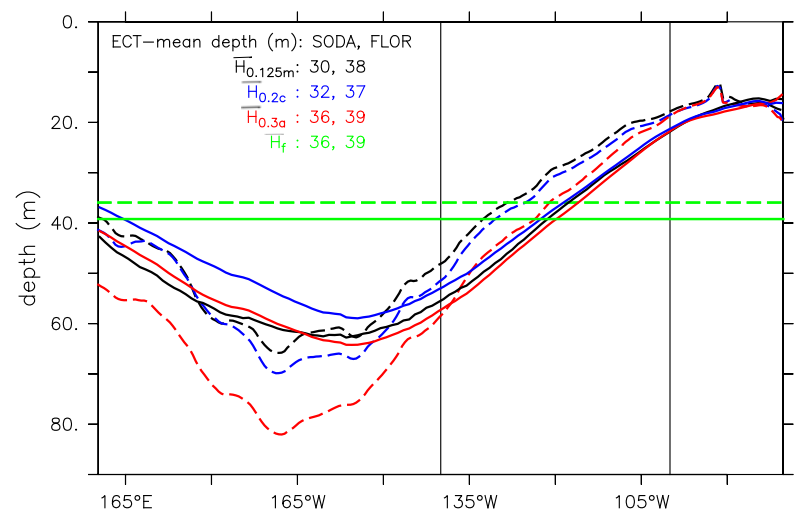

FIG. 4. Climatological annual-mean SML depth averaged between $2^{\circ} \mathrm{S}$ and $2^{\circ} \mathrm{N}$, from the SODA 2.2.4 reanalysis (dashed) and FLOR control simulation (solid), computed using $H_{0.125 \mathrm{~m}}$ (black), $H_{0.2 \mathrm{c}}$ (blue), $H_{0.3 \mathrm{a}}$ (red), and $H_{\mathrm{f}}$ (green). See section $3 \mathrm{c}$ for $H$ notation. Vertical lines indicate the longitudinal extent of the equatorial cold tongue $(\mathrm{ECT})$ box $\left(2^{\circ} \mathrm{S}-2^{\circ} \mathrm{N}, 140^{\circ}-100^{\circ} \mathrm{W}\right) ; H_{\mathrm{f}}$ is set equal to the spatial mean of $H_{0.3 \mathrm{a}}$ over the ECT box. Legend lists the ECT-mean depth for each SML definition for SODA (first) and FLOR (second).

the annual-mean climatological average $T$ and $S$. The $H_{0.3 \mathrm{a}}$ in FLOR resembles that in SODA 2.2.4 for the basin-mean and ECT region, although FLOR's $H_{0.3 \mathrm{a}}$ is $10-20 \mathrm{~m}$ shallower in the equatorial western and central Pacific.

Figure 4 shows how the 30 -yr mean $\bar{H}_{0.2 \mathrm{c}}, H_{0.3 \mathrm{a}}$, and $H_{\mathrm{f}}$ differ from $\bar{H}_{0.125 \mathrm{~m}}$. Note that $\bar{H}_{0.2 \mathrm{c}}$ is generally within $5 \mathrm{~m}$ of $\bar{H}_{0.125 \mathrm{~m}}$, except near the date line where $\bar{H}_{0.2 \mathrm{c}}$ is up to $10 \mathrm{~m}$ deeper. In FLOR $H_{0.3 \mathrm{a}}$ is generally within $5 \mathrm{~m}$ of $\bar{H}_{0.125 \mathrm{~m}}$ between $5^{\circ} \mathrm{S}$ and $5^{\circ} \mathrm{N}$, although up to $15 \mathrm{~m}$ shallower outside that latitude band. However, $H_{\mathrm{f}}$ does a much poorer job, differing from $\bar{H}_{0.125 \mathrm{~m}}$ by over $20 \mathrm{~m}$, even along the equator. Thus to approximate $\bar{H}_{0.125 \mathrm{~m}}$, it appears to be essential to retain the spatial, but perhaps not the temporal, variation in SML depth. We shall therefore focus on $H_{0.3 a}$ as a way to simplify the budget analysis while still capturing the basic structure of the 30-yr mean SML depth within the Pacific equatorial band.

Retaining the spatial variation of layer depths will help to ensure that the time-mean Equatorial Undercurrent (EUC), which flows mainly parallel to the timemean isopycnals, will flow mostly parallel to the base of the box without penetrating it; the residual diapycnal time-mean flow can then be more cleanly interpreted as Ekman upwelling. Temporal variations in the EUC slope (e.g., during ENSO) will sometimes allow the EUC to penetrate the motionless base of the box; this is a limitation of any such stationary-volume approach, and will tend to accentuate the apparent role of bottom-induced cooling of the layer during La Niña (when the EUC slope steepens and flows slightly inward through the sloping bottom of the box) and diminish that role during El Niño (when the EUC slope flattens and flows slightly outward through the sloping bottom of the box). For this reason, future studies focused mainly on understanding the temporal variability of the heat budget (rather than the time mean as in the present study) might benefit from applying the full spatiotemporally varying layer approach discussed earlier.

\section{c. Closure of the layer temperature budget}

For all of the layer depth definitions $H$ that we have considered, the diagnostic error in the total temperature tendency-determined from the actual total tendency minus the right-hand side of (2) - is very nearly zero. This small error stems from two sources: linear interpolation of the monthly-mean $T$ to the start and end of each month $[t \pm(\Delta t / 2)]$ when computing the left-hand side of (2), and a similar interpolation of $T, S, D$, and $T_{D}$ when computing the detrainment term (A2) on the right-hand side of (2). The monthly and climatologically varying SMLs $\left(H_{0.125 \mathrm{~m}}\right.$ and $H_{0.2 c}$ ) exhibit small but noticeable errors in the detrainment term, approaching $0.5 \mathrm{~K} \mathrm{yr}^{-1}$ in the offequatorial eastern Pacific. In contrast, the stationary SMLs $\left(H_{0.3 \mathrm{a}}\right.$ and $\left.H_{\mathrm{f}}\right)$, for which the detrainment term vanishes, demonstrate nearly perfect time-mean closure, with 30-yr mean SML temperature tendency errors below $0.05 \mathrm{~K} \mathrm{yr}^{-1}$ practically everywhere in the tropical Pacific.

\section{d. Two-layer decomposition}

As discussed in section 3c, it is desirable for the SML to be shallow enough that its temperature is highly correlated with SST. Figure 5a shows that the correlation between monthly-mean SST and $T_{0.3 \mathrm{a}}$ exceeds $95 \%$ over the entire basin, and $97 \%$ within the ECT. The correlation with SST drops off rapidly for layers exceeding that thickness, both along the equator (Fig. $5 \mathrm{c}$ ) and meridionally within the longitudes spanned by the ECT (Fig. 5d).

Figure 5e highlights another, thicker layer of interest along the equator, extending from the surface to near the thermocline, which subsumes both the SML and the convergence zone of the downward diffusive heat fluxes. We call this the "advective layer" (AL), since it subsumes nearly all of the advective fluxes needed to balance the time-mean vertical diffusive fluxes and surface heat flux. The $H_{1.4 a}$ layer is sufficiently deep to encompass this zone, both along the equator (Fig. 5e) and away from the equator (Fig. 5f). The AL essentially corresponds to the zone of strong vertical mixing, associated with small values of the Richardson number: 
(a) Monthly correlation of SMLT with SST

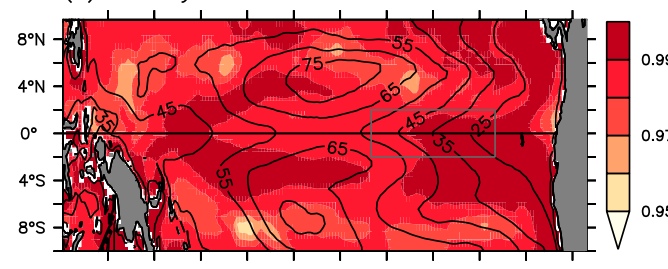

(c) Correl of temp with SST at equator

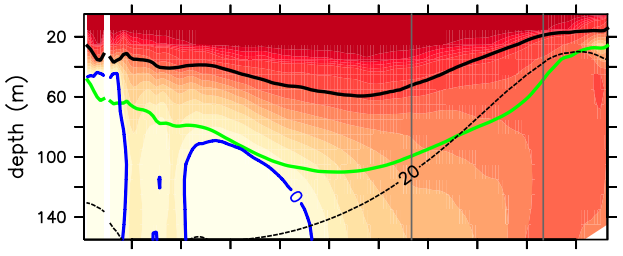

(e) Mean vertical diffusive heating at equator

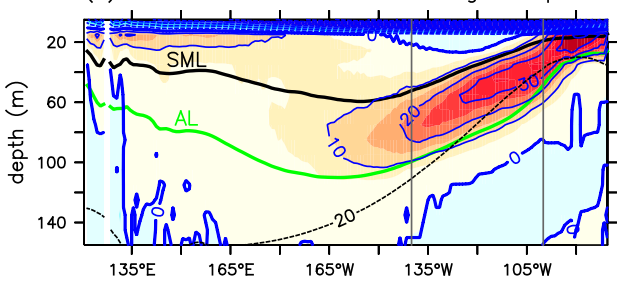

(b) Monthly correlation of ALT with SST

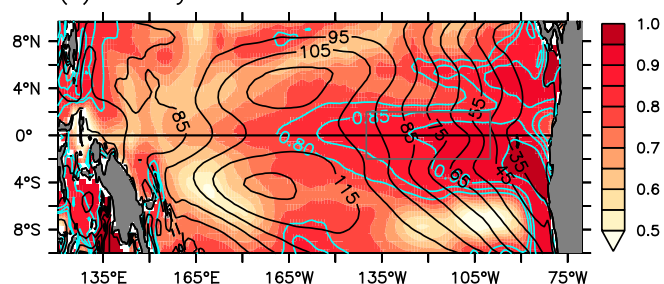

(d) ECT zonal-mean correl of temp with SST

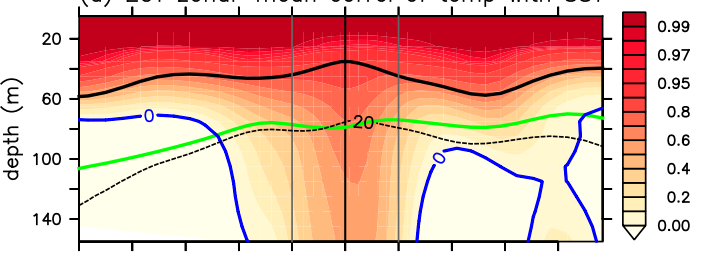

(f) ECT zonal-mean vertical diffusive heating

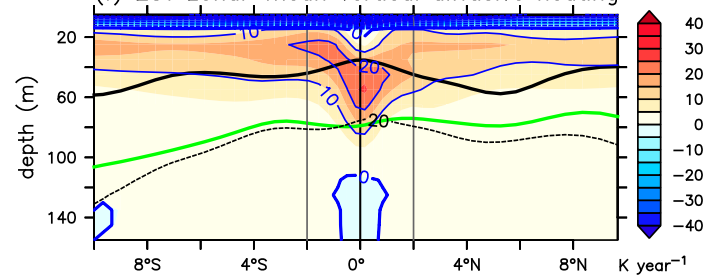

FIG. 5. Layer structures in the 30-yr FLOR control simulation. (a) Local correlation (shaded) between the monthly-mean SST and the monthly-mean temperature $\left(T_{0.3 \mathrm{a}}\right)$ of a stationary surface mixed layer (SML) whose thickness $\left(H_{0.3 \mathrm{a}}\right)$ is indicated by the black contours. (b) As in (a), but for the monthly-mean temperature $\left(T_{1.4 \mathrm{a}}\right)$ of an advective layer (AL) with thickness $H_{1.4 a}$. Light blue contours indicate correlations of 0.8, 0.85, 0.9, and 0.95. (c) Equatorial correlation between monthly-mean temperature and monthly-mean SST, SML depth (thick black curve), AL depth (solid green curve), and $20^{\circ} \mathrm{C}$ isotherm depth (thin dashed black curve). (d) As in (c), but correlations are now zonally averaged between $140^{\circ}$ and $100^{\circ} \mathrm{W}$. (e) As in (c), but shading is now the equatorial timemean vertical diffusive heating (blue contours, with shading incremented every half-contour). (f) As in (e), but diffusive heating is now zonally averaged between $140^{\circ}$ and $100^{\circ} \mathrm{W}$. The ECT region is indicated by a gray box in (a) and (b), and gray vertical lines in (c)-(f).

$$
\mathrm{Ri}=\frac{N^{2}}{S_{z}^{2}}=\frac{-g \rho_{0}^{-1} \partial_{z} \rho}{\left(\partial_{z} u\right)^{2}+\left(\partial_{z} v\right)^{2}},
$$

where $N$ is the buoyancy frequency, $S_{z}$ is the magnitude of the vertical shear of the current, $\rho$ is the potential density, and $g$ is the acceleration due to gravity. Within the ECT region, the AL base lies just above the core of the EUC and thermocline, where the vertical shear is weak and stratification is large, giving a large Ri that suppresses vertical mixing.

In contrast to the SML temperature, the AL temperature has a weaker monthly correlation with SST (Fig. 5b): only $90 \%$ in the ECT, and $50 \%$ in the southeast tropical Pacific. However, the AL is dynamically important during ENSO, and will be useful for understanding the diffusive heat fluxes out of the SML.

We further define an "advective-diffusive layer" (ADL), which is the layer of maximum vertical diffusive warming and advective cooling. The ADL generally sits between 15 and $100 \mathrm{~m}$ in the tropical Pacific. In the ECT where upwelling is strong, the ADL sits roughly between the SML base and AL base (Fig. 5e); thus for simplicity in this study, we shall simply refer to that zone as the ADL. (However, we note that in the west Pacific and off-equator area, the ADL lies mostly within the SML; Fig. 5f.) Along the equator the SML, AL, and ADL all slope upward from about $160^{\circ} \mathrm{W}$ to the eastern boundary, in tandem with the thermocline slope. The downward diffusive heat flux into the ADL is strongest in the eastern equatorial Pacific, where a shallow thermocline generates intense vertical-advective cooling, cold SSTs, and strong surface heating from airsea fluxes.

In short, we shall conceptualize the ECT as consisting of two vertical layers: 1) an SML, whose temperature is highly correlated with SST and driven mainly by surface fluxes and vertical diffusion, and 2) a thicker AL, whose temperature is driven mainly by surface fluxes and monthly advection, and within which vertical diffusion redistributes heat from the SML into the ADL. (These 
layers are illustrated schematically in Fig. 9, to be discussed later.)

While our two-layer analysis of the time-mean ECT temperature budget can help guide future studies, the SML, AL, and ADL definitions will need to be tailored to the particular application, region, and time scale of interest to the investigator. This requirement is evident in Figs. 5e and 5f, which shows that $H_{0.3 \mathrm{a}}$ (black line) sits above the zone of vertical diffusive heating within the ECT, but below it in the western equatorial Pacific and off-equator areas. A shallower SML (smaller $\Delta \sigma$ ) may be more appropriate in those regions, such as under the atmospheric convective zones where strong transient salinity stratification can detach SST from the SML temperature (as suggested by the reduced off-equatorial correlations between SST and $T_{0.3 \mathrm{a}}$ in Fig. 5a). In addition, the shorter the time scale being considered, the greater the importance of entrainment and detrainment for a time-varying SML (Fig. 2a), and the greater the variability of near-surface thermal stratification (resulting in more detachment of the SST from the SML temperature). Reducing $\Delta \sigma$ can help enhance the correlation of SST with SML temperature, though at the cost of stronger impacts of diurnal variations on the SML temperature budget. Future studies could explore whether an isothermal layer analysis (using $\Delta T$ rather than $\Delta \sigma$ as the SML criterion) may be more informative for certain applications, and whether an expansion of the analysis to three or more layers could capture more of the subsurface dynamics relevant to SST.

\section{e. Lateral structure of the annual-mean SML temperature tendencies}

Figure 6 shows the near-equatorial zonal structure of the annual-mean SML temperature tendencies from net surface heat fluxes, parameterized vertical diffusion, and all remaining terms, for various SML definitions. In the eastern equatorial Pacific, the monthly-varying $H_{0.125 \mathrm{~m}}$ exhibits strong surface flux heating balanced mainly by vertical diffusive cooling, with a much smaller cooling contribution from the remaining (mainly advective) terms. This qualitative balance holds in the west as well, where all terms are much weaker. The term $H_{0.2 c}$, which removes year-to-year variations of SML depth while retaining the seasonal cycle, shows a similar pattern though with a slight weakening of the surface flux heating and vertical diffusive cooling in the ECT, and a relatively greater role for the remaining terms. The stationary $H_{0.3 \mathrm{a}}$ also shows a similar pattern, with further slight weakening of the dominant balance and a greater role for the remaining terms.

In the ECT, as in most of the rest of the tropical Pacific, $H_{0.125 \mathrm{~m}}$ is temporally anticorrelated with the surface

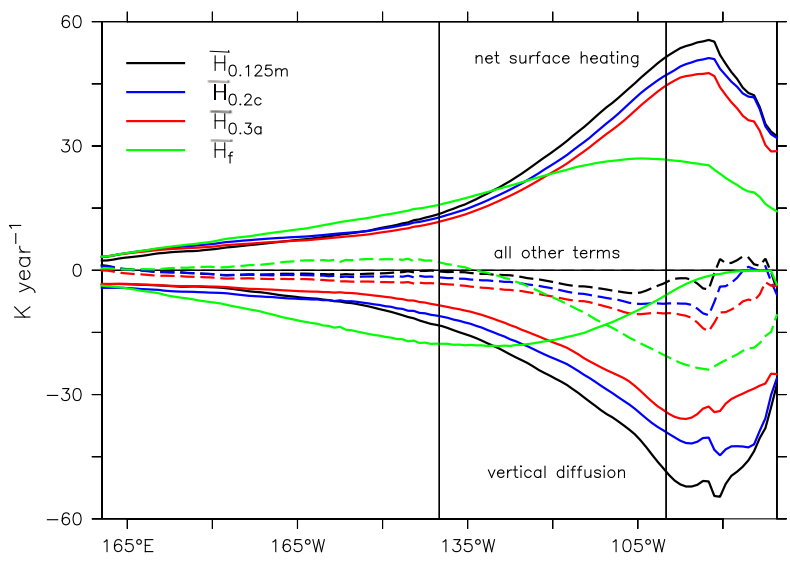

FIG. 6. Ocean temperature time-mean tendencies $\left(\mathrm{K} \mathrm{yr}^{-1}\right)$ from the FLOR control simulation, averaged over $2^{\circ} \mathrm{S}$ and $2^{\circ} \mathrm{N}$ and over the SML: net surface flux heating minus solar penetration (positive), parameterized vertical diffusion (negative), and all other terms (middle; dashed). Colors indicate the SML definition used: $H_{0.125 \mathrm{~m}}$ (black), $H_{0.2 \mathrm{c}}$ (blue), $H_{0.3 \mathrm{a}}\left(\right.$ red), or $H_{\mathrm{f}}=39 \mathrm{~m}$ (green). All budget terms are diagnosed by the full ocean model at its hourly time step. Vertical lines show the longitudinal span of the equatorial cold tongue box.

heat flux: shallow SMLs tend to coincide with intensifications of the surface heating, amplifying the SML temperature response, while deep SMLs tend to coincide with reductions in the surface heating, diluting the SML temperature response. This effect rectifies in the time mean, boosting the time-mean role of the surface flux heating for $H_{0.125 \mathrm{~m}}$ relative to $H_{0.3 \mathrm{a}}$. Similarly, $H_{0.125 \mathrm{~m}}$ tends to shoal during times of vigorous diffusive cooling (e.g., La Niña and boreal summer), so that $H_{0.125 \mathrm{~m}}$ subsumes less of the vertical diffusive heat flux and thus cools more than the $H_{0.3 \mathrm{a}}$ layer, both during these events and in the time mean. These rectified effects are rather small in FLOR, but they are fractionally greater for the vertical diffusion than the surface heat flux, which leads to a proportionately greater change in the remaining (mainly advective) terms.

The fixed-depth $H_{\mathrm{f}}=39 \mathrm{~m}$ does a much poorer job than $H_{0.3 \mathrm{a}}$ of emulating the $H_{0.125 \mathrm{~m}}$ layer's strong lateral contrasts in SML heating near the ECT, with the balance between surface fluxes and vertical diffusion being far too weak in the east, and too strong in the central/ western equatorial Pacific. Also, $H_{\mathrm{f}}$ shows a much stronger role for the advective cooling in the east, and actually flips the sign of these terms west of the ECT. This is because $H_{\mathrm{f}}$ tends to be too deep in the shallowthermocline regions (diluting the effect of the surface fluxes on the local SML, subsuming more of the vertical diffusive heat flux, and including more deep vertical advective cooling) and too shallow outside these regions (amplifying the effect of the surface fluxes on the local 
Monthly advective heating

(a) $\mathrm{H}_{0.125 \mathrm{~m}}$

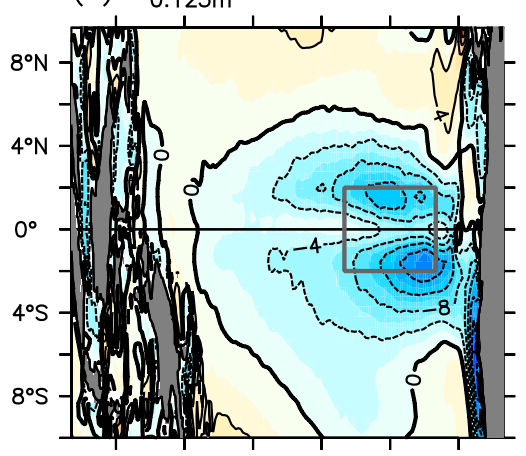

(d) $\mathrm{H}_{0.3 a}-\mathrm{H}_{0.125 m}$

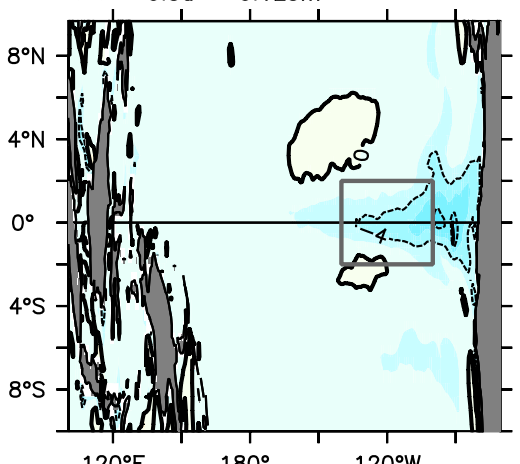

$120^{\circ} \mathrm{E}$
Submonthly advective heating

(b) $H_{0.125 m}$

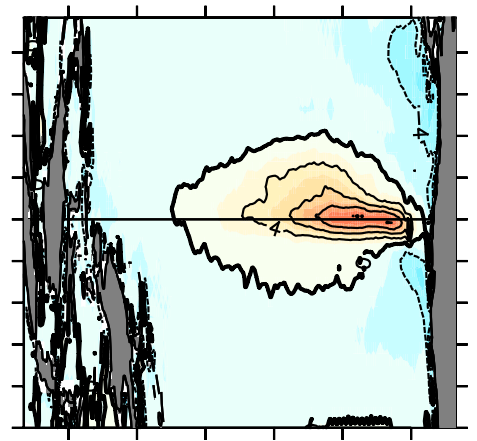

(e) $\mathrm{H}_{0.3 \mathrm{a}}-\mathrm{H}_{0.125 \mathrm{~m}}$

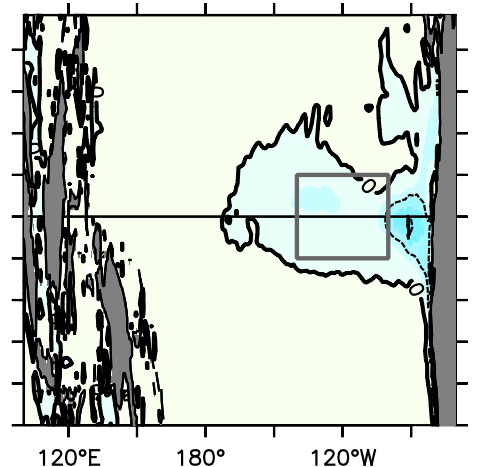

Net residual heating

(c) $\mathrm{H}_{0.125 \mathrm{~m}}$

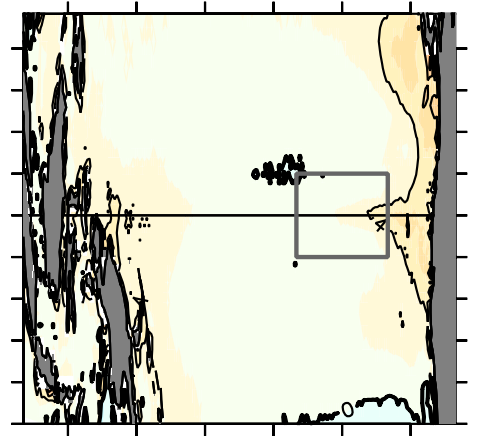

(f) $\mathrm{H}_{0.3 \mathrm{a}}-\mathrm{H}_{0.125 \mathrm{~m}}$

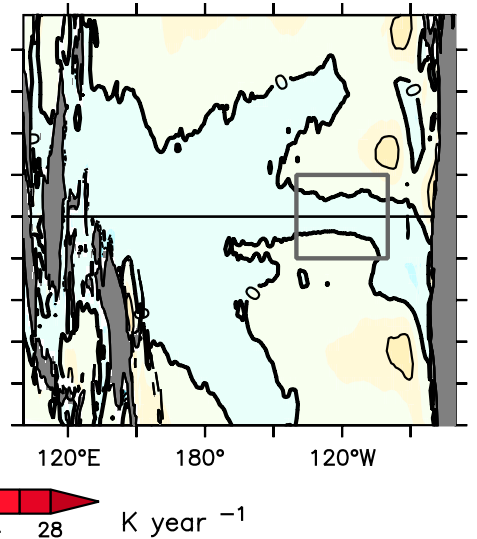

FIG. 7. SML advective temperature tendencies $\left(\mathrm{K} \mathrm{yr}^{-1}\right)$ in the FLOR control run, for (a) monthly advection within $H_{0.125 \mathrm{~m}}$, calculated using monthly-mean currents and monthly-mean temperatures; (b) submonthly advection within $H_{0.125 m}$, diagnosed from the total modeldiagnosed advection (using hourly fields) minus the monthly advection in (a); and (c) residual tendency due to all terms other than the surface flux, solar penetration, local diffusion due to vertical mixing, and total hourly resolved advection. (d)-(f) The respective change in each tendency term when using the stationary $H_{0.3 \mathrm{a}}$ rather than the evolving $H_{0.125 \mathrm{~m}}$. Shading is incremented every half contour.

SML, subsuming less of the diffusive flux, and exaggerating the role of the near-surface submonthly meridionaladvective warming compared to the deeper monthly vertical-advective cooling). We conclude that retaining the spatial variation of $H_{0.3 \mathrm{a}}$ is essential to emulate the time-mean balance of tendency terms exhibited by $H_{0.125 \mathrm{~m}}$ along the equator.

Figure 7 shows the lateral structure of the annualmean advective and residual temperature tendencies of the SML. The term $H_{0.125 \mathrm{~m}}$ shows monthly advective cooling (associated mainly with wind-driven Ekman flow) mainly on the poleward flanks of the ECT and along the coast of South America, with some warming poleward of $6^{\circ}$ latitude. It also shows submonthly advective warming near the equator within the ECT (associated mainly with TIWs), and cooling outside the equatorial band and along the eastern boundary. The term $H_{0.3 a}$ generally captures these advective patterns, although with stronger monthly cooling and weaker submonthly warming in the ECT, especially very near the equator and toward the eastern boundary. This is likely due to the tendency of $H_{0.125 \mathrm{~m}}$ to shoal relative to $H_{0.3 \mathrm{a}}$ during times of vigorous advection within the ECT (e.g., La Niña and boreal autumn); $H_{0.125 m}$ then subsumes less of the monthly advective cooling that is concentrated below the SML, and amplifies the submonthly advective warming that is concentrated at the surface.

\section{f. Annual-mean temperature budget of the ECT}

\section{1) SURFACE MIXED LAYER}

Figure 8 shows the climatological annual-mean temperature budget of the ECT region in the FLOR control simulation, using various definitions of the SML and AL. For an SML diagnosed from monthly varying $T$ and $S$ (i.e., $\left.H_{0.3 a}\right)$ the surface flux heating in FLOR is balanced primarily by the monthly advective cooling and parameterized 


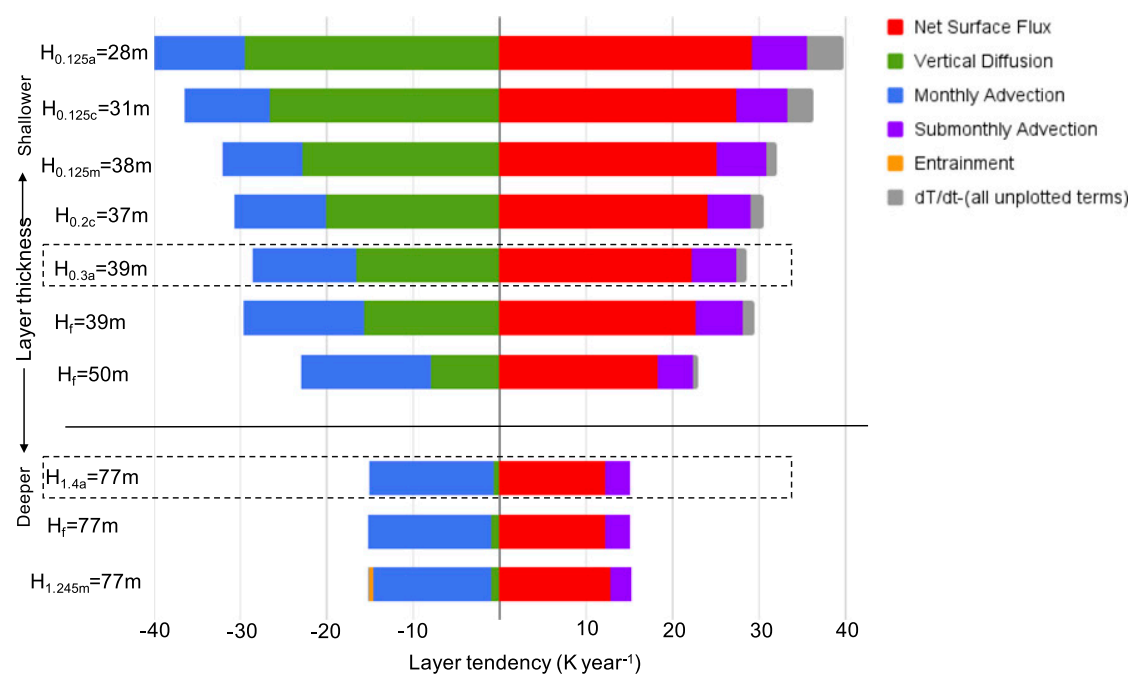

FIG. 8. Annual-mean climatological tendency terms $\left(\mathrm{K} \mathrm{yr}^{-1}\right)$ in the FLOR control simulation, volume-averaged over the cold tongue box $\left(2^{\circ} \mathrm{S}-2^{\circ} \mathrm{N}, 140^{\circ}-100^{\circ} \mathrm{W}\right)$, for various layer thicknesses indicated on the ordinate (see Fig. 2 caption). The label $H_{0.125 \mathrm{a}}=28 \mathrm{~m}$ indicates a density criterion of $\Delta \sigma_{\text {crit }}=0.125 \mathrm{~kg} \mathrm{~m}^{-3}$ applied to the climatological annualmean $T$ and $S$ fields, whose spatial-mean depth within the cold tongue box is $28 \mathrm{~m}$. Volumemean tendency terms are computed hourly (except for entrainment, which is computed from monthly model output), and then averaged in time. The budget terms shown are net surface heat flux minus the solar flux penetrating through the mixed layer base (red), vertical diffusion (green), total three-dimensional advection (blue), submonthly advection (purple), entrainment (orange), and the residual tendency due to all other terms (gray). The time-mean entrainment cooling due to monthly layer undulations (orange) is very weak, and in fact vanishes for stationary layers like the $H_{0.3 \mathrm{a}}$ and $H_{1.4 \mathrm{a}}$ (dashed boxes) that we selected for detailed analysis.

vertical diffusive cooling, countered by some warming from submonthly advection. The net time-mean effect of all the remaining terms (gray bar) is very small.

As mentioned earlier, time-averaging the $T$ and $S$ fields before applying the $\Delta \sigma_{\text {crit }}$ criterion affects the time-mean SML depths. With increasing averaging, the ECT SML shoals from $\bar{H}_{0.125 \mathrm{~m}}=38 \mathrm{~m}$, to $\bar{H}_{0.125 \mathrm{c}}=$ $31 \mathrm{~m}$, to $\bar{H}_{0.125 \mathrm{a}}=28 \mathrm{~m}$. This thinning then amplifies the SML temperature response to the surface heat flux, which in turn must be compensated by a strengthening of the other budget terms. Adjusting $\Delta \sigma_{\text {crit }}$ so that the time-mean SML depths are roughly similar for the various timeaveraging schemes gives $\bar{H}_{0.125 \mathrm{~m}}=38 \mathrm{~m}, \bar{H}_{0.2 \mathrm{c}}=37 \mathrm{~m}$, and $\bar{H}_{0.3 \mathrm{a}}=H_{\mathrm{f}}=39 \mathrm{~m}$.

Figure 8 shows that the time-mean ECT budgets for $H_{0.2 \mathrm{c}}, H_{0.3 \mathrm{a}}$, and $H_{\mathrm{f}}=39 \mathrm{~m}$ all closely resemble that for $\bar{H}_{0.125 \mathrm{~m}}$, apart from the somewhat weaker budget tendencies and greater relative role for monthly advection as described in section 4e. In contrast, the occasionally used $H_{\mathrm{f}}=50 \mathrm{~m}$ (e.g., Zebiak and Cane 1987) is too deep to closely emulate the $\bar{H}_{0.125 \mathrm{~m}}$ budget over the ECT; $H_{\mathrm{f}}=50 \mathrm{~m}$ extends too deep into the advective regime (Fig. 8) and also weakens the correlations of the SML temperature with SST (Fig. 5).

\section{2) Advective LAYER}

The budget of the AL is simpler than that for the SML, since the AL is sufficiently thick to subsume most of the vertical diffusive fluxes, strong vertical and lateral gradients, and strong temporal variations that occur near the surface. Figure 8 shows that for $H_{1.245 \mathrm{~m}}$ the surface flux heating in the ECT is balanced almost entirely by monthly advective cooling, with a small warming contribution from submonthly advection, and an even smaller contribution from vertical diffusive cooling. Effects of entrainment and all other remaining terms are negligible. The AL budget of the ECT is also insensitive to the method used to define the AL: $H_{1.4 a}$ and even a constant $H_{\mathrm{f}}=77 \mathrm{~m}$ both give temperature budgets that are very similar to the monthly-varying $H_{1.245 \mathrm{~m}}$.

\section{3) SCHEMATIC SUMMARY}

The combination of excellent budget closure, representative time-mean layer thicknesses and term balances within the ECT, and ease of interpretation motivate our focus hereafter on a spatially varying but temporally stationary SML $\left(H_{0.3 \mathrm{a}}\right)$ and $\mathrm{AL}\left(H_{1.4 \mathrm{a}}\right)$. Figure 9 shows a 
(a) Surface mixed layer

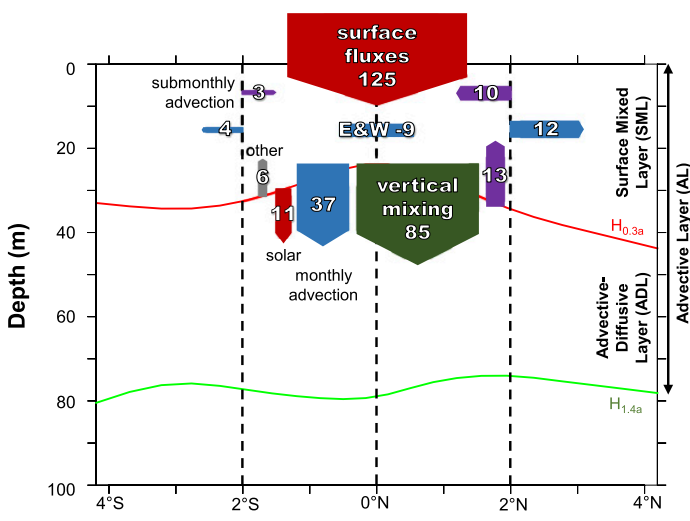

(b) Advective layer

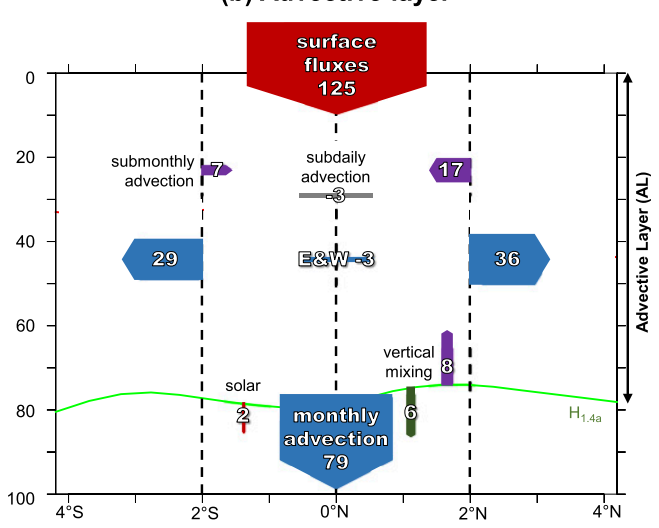

FIG. 9. Meridional structure of the fluxes across the faces of the equatorial cold tongue box, for volumes spanning $2^{\circ} \mathrm{S}-2^{\circ} \mathrm{N}, 140^{\circ}-100^{\circ} \mathrm{W}$ and extending from the sea surface to either (a) the SML depth $\left(H_{0.3 \mathrm{a}}\right)$ or (b) the AL depth $\left(H_{1.4 a}\right)$. Directional advective fluxes are expressed relative to the volume-mean temperature of the SML in (a) and of the AL in (b). Arrow thickness is proportional to the flux magnitude, expressed in $\mathrm{W} \mathrm{m}^{-2}$ of ECT horizontal area. (The ECT horizontal area is $2.0 \times 10^{12} \mathrm{~m}^{2}$, so doubling these values converts them to power in terawatts.) The advective flux across each layer's sloping base is the sum of the vertical flux plus the zonal and meridional inductive fluxes across the layer base. Colors indicate fluxes due to air-sea exchange and solar penetration (red), vertical mixing (green), monthly advection (blue), submonthly advection (purple), and other processes (gray). The subdaily advection (gray bar) and the sum of the monthly zonal advective fluxes across the eastern and western faces of the ECT box (blue bar) use the same vertical thickness scale as the meridional advective fluxes (horizontal blue and purple arrows). The SML and AL zonal submonthly advection, SML subdaily advection, and AL residual are all weaker than $0.5 \mathrm{~W} \mathrm{~m}^{-2}$ and are not shown.

schematic summary of the time-mean ECT temperature budget in FLOR, based on the results in Fig. 8 and the directional decomposition to be discussed next in section 5 .

Figure 9 shows that heat enters the ECT SML via surface fluxes (mainly solar). Less than $9 \%$ of the total solar flux penetrates the SML to heat the ADL, and less than $2 \%$ escapes through the base of the AL.

The SML is also weakly heated via submonthly advective fluxes at the northern, southern, and bottom faces of the ECT box. These submonthly advective effects may be weaker in FLOR than the real world, in part because FLOR's TIW variance is weaker than observed (Wittenberg et al. 2018).

Less than half of the total SML heating is balanced by monthly advective (mainly vertical) cooling of the SML. The remaining heat diffuses down through the SML base and into the ADL, where it must be balanced almost entirely by relatively cooler water flowing in at monthly time scales through the northern, southern, and bottom faces of the ECT ADL box.

Figure $9 \mathrm{~b}$ shows that for the AL as a whole, the primary thermal balance is between the surface flux heating, and the monthly advective cooling at the northern, southern, and bottom faces of the ECT AL box. Submonthly advection contributes substantial mean warming of the $\mathrm{AL}$, by stirring in relatively warmer water mainly at the northern face of the box. The direct net effects of zonal advection and vertical mixing on the ECT AL time-mean temperature are very small.

\section{Directional decomposition of advection}

\section{a. Surface mixed layer}

Figure 10 shows the lateral structure of FLOR's advective temperature tendency of the local SML, decomposed into directional and temporal components. Advection at monthly and longer time scales (Figs. 10a,d,f,h) tends to cool the SML near the equator and in the coastal zone near South America, mainly via vertical advection (i.e., upwelling of cold water). The cold ECT water is then advected poleward and westward by the monthly-mean currents, broadening the ECT and displacing it westward. Monthly zonal advection also cools the SML near Peru and warms it near the equator, helping to broaden the cold zone near the coast and displace it southward.

The monthly advective cooling of the ECT SML (Figs. 10a and 12a) is partly offset by submonthly advective warming (Figs. 10b and 13a), associated mainly with submonthly TIW activity, so that cooling from parameterized vertical mixing must play the dominant role within the SML of balancing the heating due to surface fluxes (Fig. 6). In FLOR's SML, the resolved submonthly vertical cooling is generally weak and is largely offset by weak submonthly zonal warming. 
SML advective heating $\left(\mathrm{K}_{\text {year }}{ }^{-1}\right): \mathrm{H}_{0.3 a}$

(a) Total

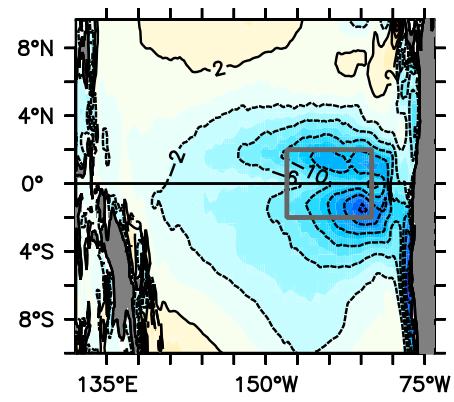

(d) Zonal

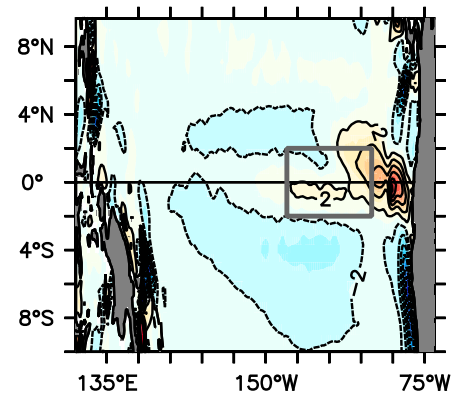

(f) Meridional

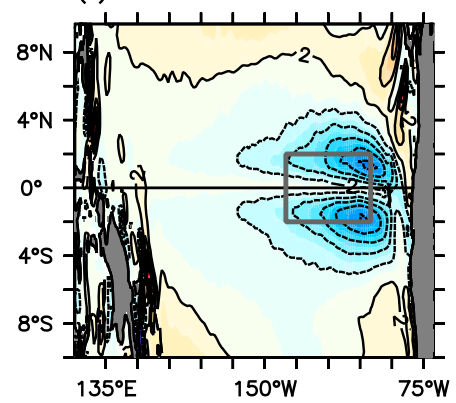

(h) Vertical

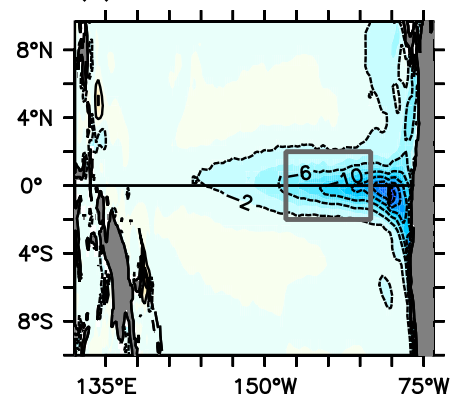

(b) Total

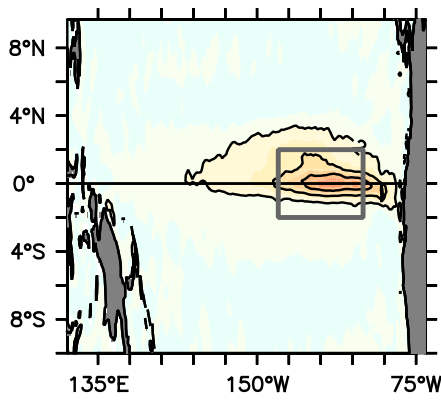

(e) Zonal

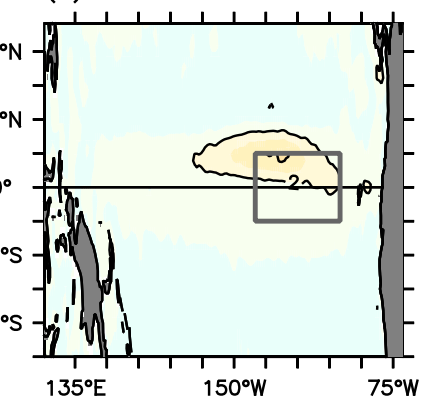

(g) Meridional

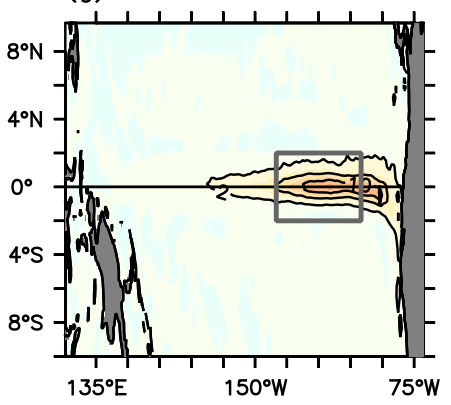

(i) Vertical

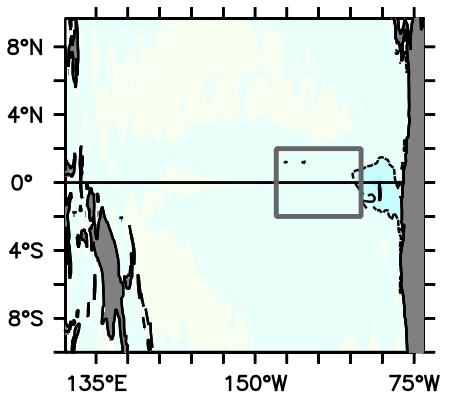

(c) Total Subdaily

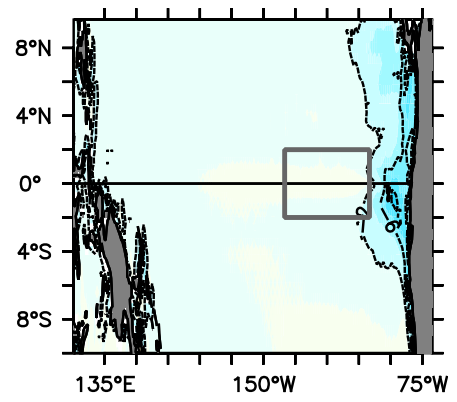


Subdaily advection (Fig. 10) is also relatively weak, although it does contribute some cooling of the SML very near the eastern boundary, serving to weaken the strong thermal stratification there. That the subdaily variability plays a significant role in FLOR's climatological stratification and heat budget near the eastern boundary may hold implications for the warm SST biases found in that region in FLOR and most other coupled climate models. High-frequency observations of the surface fluxes, near-surface temperatures, and currents in this region (e.g., via future TPOS process studies using moorings, ships, and saildrones) could help shed light on the essential mechanisms of this diurnal variability and its rectified effects on the mean state, to better constrain model simulations.

\section{b. Advective layer}

Figure 11 shows FLOR's advective temperature tendencies vertically averaged over the full AL. Monthly advection plays a larger role than for the SML, with strong vertical cooling along the equator partly compensated by zonal warming within the ECT. The reason for this compensation is shown in Fig. 12. Along the equator, the EUC is nearly aligned with the thermocline and so produces little net advective tendency; but because both the EUC and the thermocline slope up toward the east, both the currents and the temperature gradient project into the $z$ and $x$ directions. The $z$ component represents a cooling (Fig. 12d), and the $x$ component represents a nearly compensating warming (Fig. 12b). The total monthly advection (Fig. 12a) arises from the relatively weak diathermal component of the flow and represents a cooling that is confined mainly within the ADL along the equator. This net monthly advective cooling is balanced mainly by the downward diffusive flux of heat arriving from the SML, which converges in the ADL (Fig. 5e).

Figure 11f shows that monthly meridional advection serves to spread the cold ECT water poleward, and is also the main driver of the meridional asymmetry of the ECT cooling within the AL, with stronger cooling in the southern half of the ECT box. Submonthly meridional advection (Fig. 11g) slightly warms the ECT AL near the equator, although this effect is relatively weaker for the AL than for the SML. Subdaily advection (Fig. 11c) plays very little direct role in the AL time-mean temperature, except outside the ECT near the eastern boundary.

Figure 13 shows that in the ECT region, FLOR's submonthly advective warming (associated mainly with TIW activity) along the equator is concentrated mainly in the SML, and decays rapidly with depth. The submonthly warming is almost entirely from meridional advection (with a very minor contribution from the zonal advection) and is partly countered by a submonthly vertical advective cooling below the SML, between the AL base and the thermocline. This combination of submonthly meridional warming near the surface and submonthly vertical cooling at depth assists the surface heat flux and monthly advection (Fig. 12a) in maintaining the thermal stratification of the ECT SML and AL, in the face of the destratifying effect of vertical diffusion near the surface (Fig. 5e).

Unlike the ECT, the western equatorial Pacific has little submonthly advective warming within the SML (Fig. 13a). The west Pacific submonthly meridional warming is focused mainly below the AL, and actually works to erode the near-surface thermal stratification in the west, dominating the stratifying effect of submonthly vertical cooling at depth.

\section{Summary}

The Pacific equatorial cold tongue (ECT) is a critical region governing ENSO, its global teleconnections, and its possible future changes in response to radiative forcings. To illuminate the processes controlling the time-mean SST within this key region, we have examined the temperature budget of the upper ocean using FLOR - a global coupled GCM developed by NOAA GFDL for seasonal predictions, which exhibits a more realistic climatology within the tropical Pacific than most other coupled GCMs.

Ocean heat budget analyses have been hindered in the past by enormous data requirements and incomplete closures. Our framework fully closes the heat budget, in contrast to many prior studies that involved ad hoc assumptions or a large residual term. In addition, we present practical simplifications that can enable broader application of these powerful diagnostic tools in climate simulations and ocean reanalyses.

Our analysis of the heat budget motivates partitioning the upper ocean of the ECT into two layers: 1) a surface mixed layer (SML) whose temperature is highly correlated with SST, and whose heat uptake from the atmosphere is mainly balanced by mixing-induced downward diffusion of heat across the SML base, and 2) an underlying advective-diffusive layer (ADL), in which monthlyscale vertical and meridional advection nearly balance the diffusive heat flux received from the SML. Together the SML and ADL constitute an advective layer (AL) in which the surface flux mainly balances monthly vertical and meridional advection, and within which submonthly processes redistribute heat.

We recommend against computing the temperature budget using spatially constant layer depths, which can misrepresent the spatial structure of the processes affecting SST. However, the time-mean ECT temperature 
AL advective heating $\left(K_{\text {year }}{ }^{-1}\right): H_{1.4 a}$

(a) Total Monthly

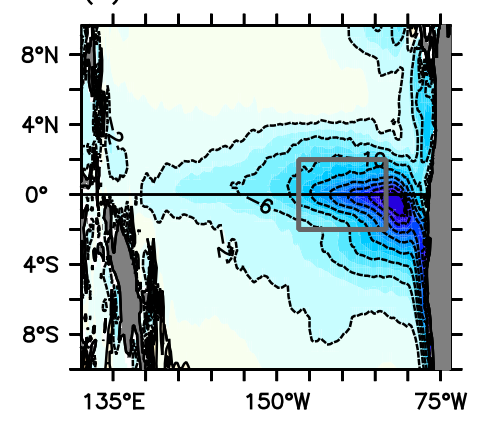

(d) Zonal

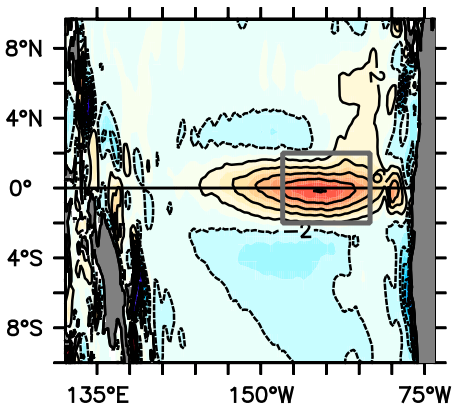

(f) Meridional

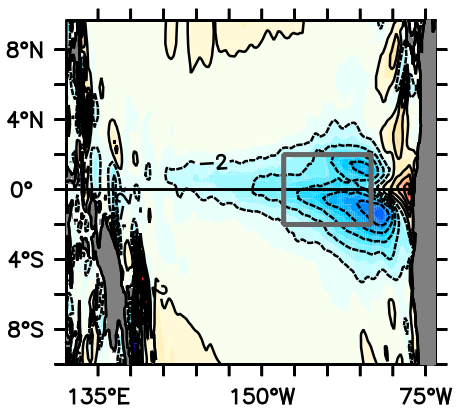

(h) Vertical

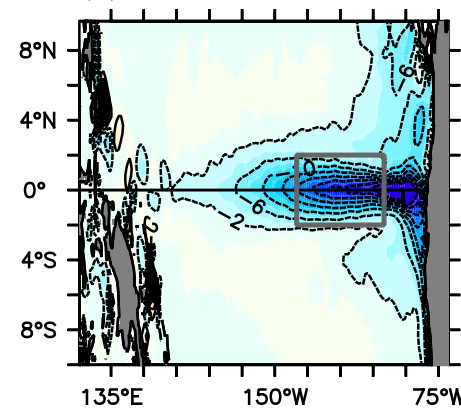

(b) Total Submonthly

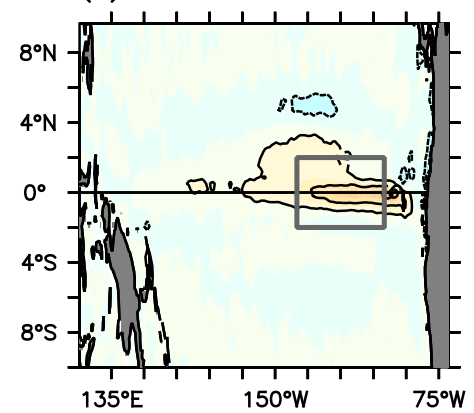

(e) Zonal

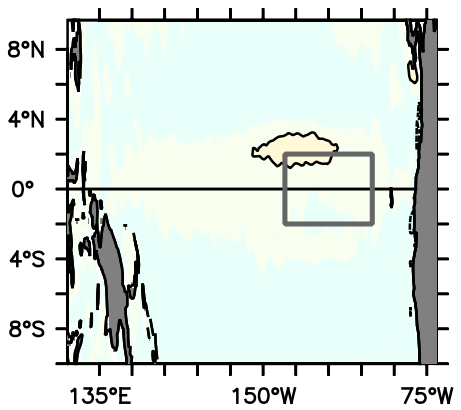

(g) Meridional

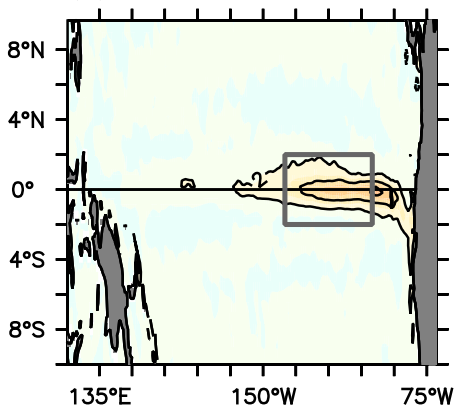

(i) Vertical

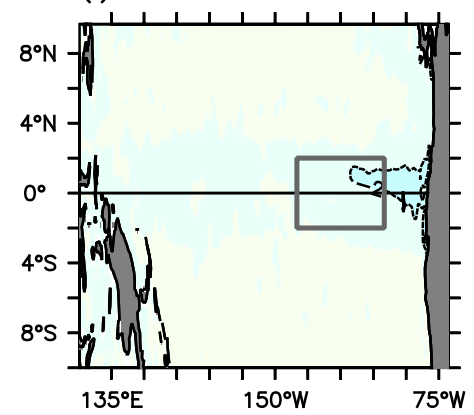

(c) Total Subdaily

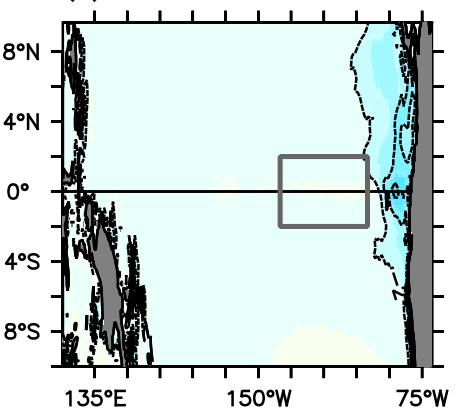

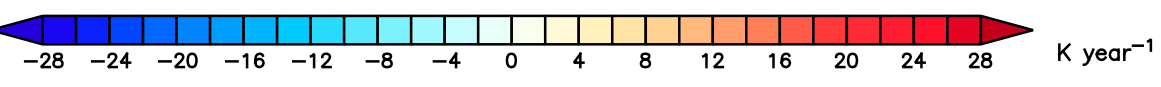

FIG. 11. As is Fig. 10, but for the AL $\left(H_{1.4 a}\right)$. 
(a) Total

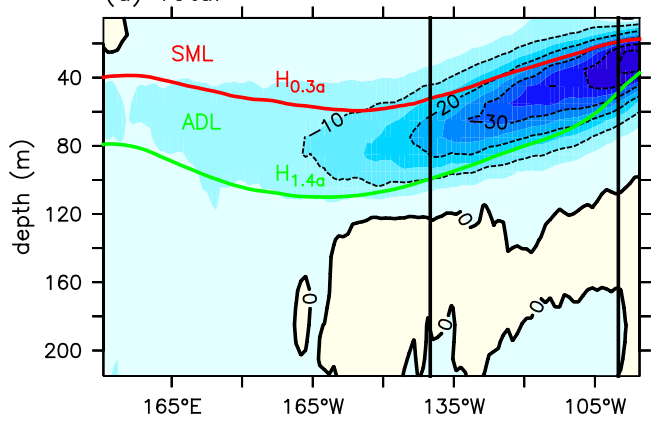

(c) Meridional

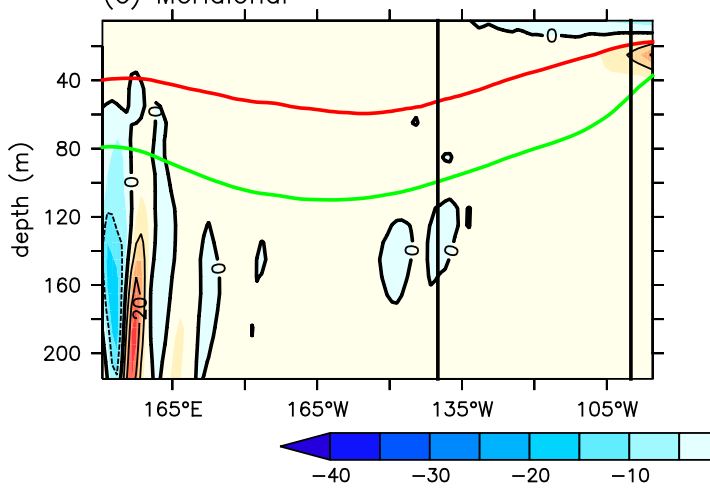

(b) Zonal

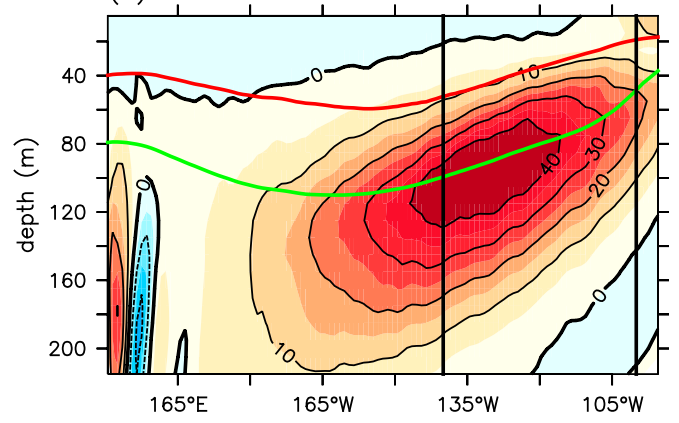

(d) Vertica

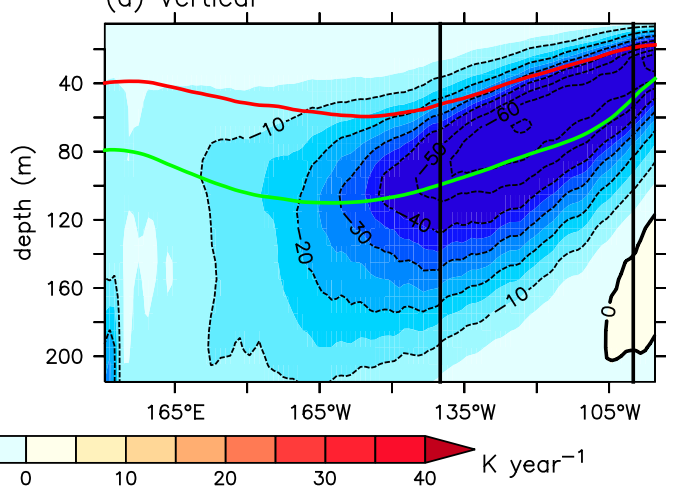

FIG. 12. Equatorial sections of simulated mean monthly advective tendencies: (a) total, (b) zonal, (c) meridional, and (d) vertical. Shading is incremented every half contour. Solid curves indicate the depths of the SML $\left(H_{0.3 a}\right.$; red) and $\operatorname{AL}\left(H_{1.4 a}\right.$; green). Vertical lines indicate the boundaries of the ECT.

budget for each layer does appear to be reasonably well represented by the time-mean heat budget for a stationary (but spatially varying) layer with the same timemean depth. The use of stationary layers eliminates the problematic entrainment/detrainment term, which can be difficult to estimate from available observations and even from model output. Stationary layers permit closure of the layer temperature budget and simplify its interpretation, facilitating application of the analysis to numerous existing datasets available from climate simulations and observational reanalyses.

Upper-ocean layer thicknesses in the ECT tend to be positively skewed. Thus to match the time-mean depths of layers diagnosed from time-varying density profiles, a larger criterion of density difference from the surface should be used when diagnosing a stationary layer depth using the time-mean density profile. For example, to match the time-mean layer depth for $\Delta \sigma_{\text {crit }}=0.125 \mathrm{~kg} \mathrm{~m}^{-3}$ applied to monthly-mean density profiles, a $\Delta \sigma_{\text {crit }}=$ $0.3 \mathrm{~kg} \mathrm{~m}^{-3}$ must be applied to the climatological annualmean density profile.

Analysis of FLOR's diurnal, seasonal, and interannual variations of the ECT layer temperature budgets reveals the key roles of the net surface heat flux (at diurnal and interannual scales), resolved advection (at submonthly, seasonal, and interannual scales), and parameterized vertical mixing (at diurnal, seasonal, and interannual scales). The net cooling of the SML due to advection and vertical diffusion is particularly strong during boreal autumn of La Niña years, with the diffusive cooling also particularly strong at night. The outsized impacts of these temporal scales and regimes on the time-mean structure of the ECT warrant additional attention to model simulations of these regimes.

We have developed a framework to summarize the equatorial Pacific upper-ocean temperature budget, which should be compatible with the output variable list planned for CMIP6. In particular, the Ocean Model Intercomparison Project component of CMIP6 (Griffies et al. 2016), which plans to archive a full set of ocean temperature budget terms from its participating model simulations, will offer a new resource for researchers looking to understand and address ocean model biases. Intercomparisons of simulated upper-ocean temperature budgets from the CMIP6 models, and evaluation of 

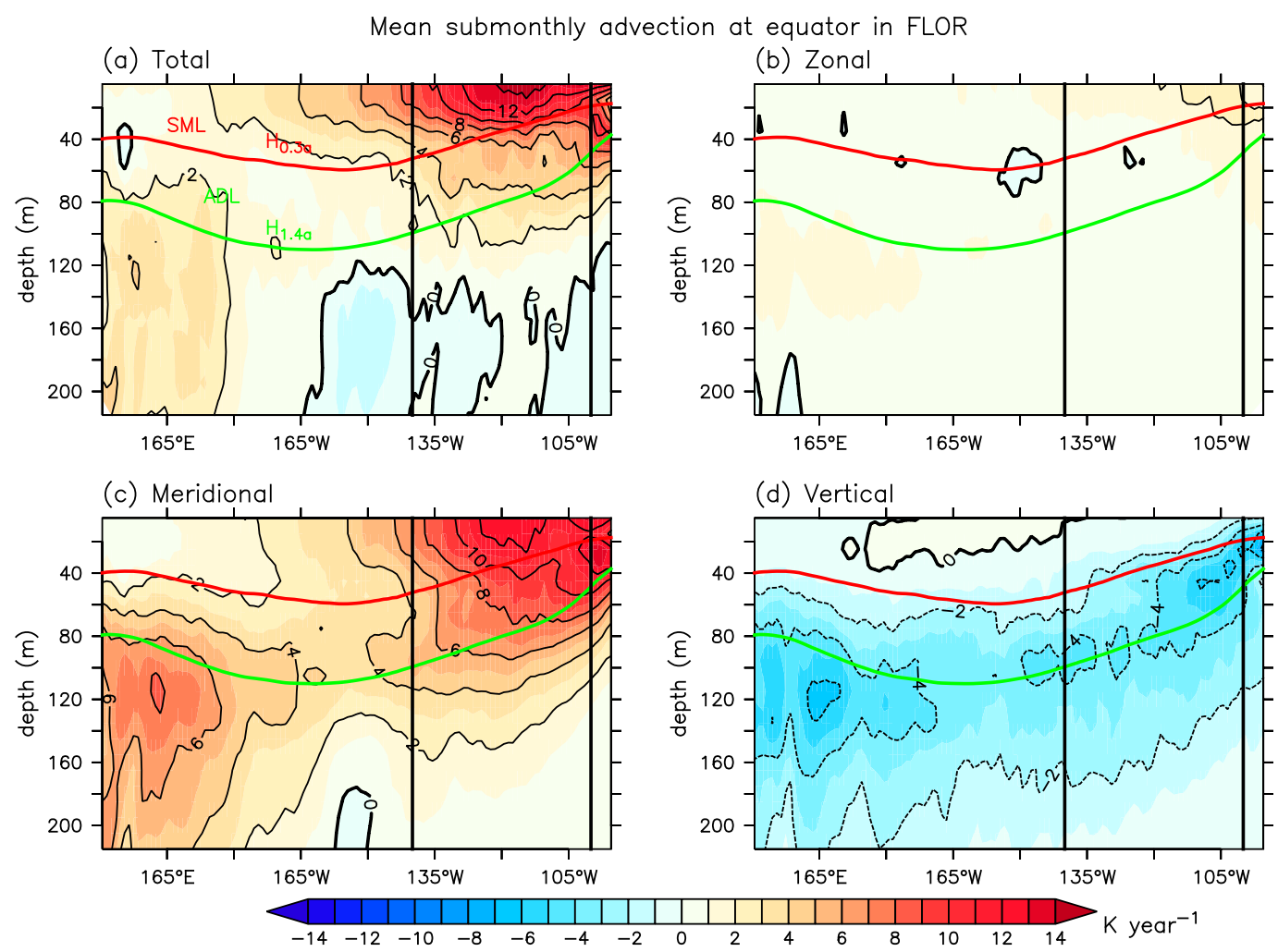

FIG. 13. As in Fig. 12, but for submonthly advection computed as in Figs. 10b, 10e, 10g, and 10i, with a compressed color scale to highlight the smaller values.

those simulations against ocean reanalyses, could help illuminate common dynamical biases.

In Part II of this paper, we further examine the ECT heat budget of the FLOR simulation and evaluate the simulation against observational ocean reanalyses. We also explore how FLOR's subsurface heat budget changes when using surface flux adjustments are used to correct the climatological surface wind stress and SST.

Acknowledgments. We thank M. Harrison, A. Rosati, and the anonymous reviewers for their constructive comments. This study was supported by NOAA GFDL, by NOAA's Climate Program Office Climate Variability and Predictability Program (Award GC14-250a), and by Princeton University's Cooperative Institute for Climate Science (CICS) under NOAA Cooperative Agreement NA14OAR4320106.

\section{APPENDIX A}

\section{Detrainment}

The detrainment term in (2) arises not from a change in the temperature of the grid cells themselves, but rather from a change in which cells are included in the domain average. The detrainment term vanishes if $h$ is stationary. However, if $h$ evolves in time, then $\partial_{t} h$ will affect the domain-averaged temperature $T_{D}$ as

$$
\langle\text { detrainment }\rangle=\frac{1}{V_{D}} \iint_{S_{-h}}\left(T_{-h}-T_{D}\right) \partial_{t} h d x d y .
$$

For the ECT the layer base is nearly always cooler than the domain as a whole, so that $T_{-h}-T_{D}<0$. Thus detrainment due to a thinning surface layer $\left(\partial_{t} h<0\right)$ tends to warm the layer as a whole, by excluding cool deep water. Conversely, entrainment due to a thickening surface layer $\left(\partial_{t} h>0\right)$ tends to cool the layer, by annexing cool deep water.

If the $\Delta \sigma$-dependent definitions of $h$ and $D$ were known in advance of the model run, then the ocean model could directly calculate (A1) at run time. However, these definitions depend on the interests of the investigator, which may change after the model has been run. Post-hoc computation of (A1) would then require saving model output at very high frequency (i.e., hourly) to precisely evaluate $T_{-h}-T_{D}, \partial_{t} h$, and their covariation; such output would likely be overly voluminous for runs beyond a few years in length. 
A simpler alternative is to diagnose the time-mean detrainment effects as a residual of the model temperature budget. Consider a time interval $[t-(\Delta t / 2), t+(\Delta t / 2)]$, and let $\Delta$ denote the change in a quantity across that interval; for example, $\Delta T=T[t+(\Delta t / 2)]-T[t-(\Delta t / 2)]$. Suppose that each of the budget terms in (2) will be volume-averaged over a particular "representative" (e.g., monthly-mean) domain $\bar{D}(t)$ during this time interval. Consider $\bar{D}(t)$ to be fixed during the interval, unlike $D(t)$ which fluctuates during the interval. We then define the time-averaged detrainment warming (referenced to $\bar{D}$ ) during the interval as

$$
\overline{\langle\text { detrainment }\rangle} \equiv \frac{\Delta T_{D}-\langle\Delta T\rangle}{\Delta t},
$$

where $\Delta T_{D}$ is the full change in volume-mean temperature across the interval (due to both the evolving cell temperatures and changing domain), and

$$
\langle\Delta T\rangle=\frac{1}{V_{\bar{D}}} \iiint_{\bar{D}} \Delta T d x d y d z
$$

is the volume-averaged temperature change within $\bar{D}$. Equation (A2) thus measures the change in $T_{D}$ stemming only from the expansion or contraction of $D$ relative to $\bar{D}$ across the interval, excluding the intrinsic warming or cooling of the fixed set of cells comprising $\bar{D}$.

\section{APPENDIX B}

\section{Diagnostic Implementation of the Temperature Budget}

The layer depth $h$ and horizontal region $R$ together define $D$ and $V_{D}$ for the volume averages in (2). To compute (3) and (4), we calculate each model cell's temperature tendencies (i.e., flux convergences) associated with the fluxes across each of the cell's six faces, and then volume-average those tendencies over $D$. Although this "volumetric" approach is less computationally efficient than performing a surface integral over $S_{D}$, it is conceptually and algorithmically much simpler to implement; it also easily generalizes to any domain (including nonconvex and noncontiguous domains) of any dimension, and works even if the domain boundary is not aligned with grid cell edges. The volume-integral and surface-integral forms are numerically equivalent, since the model satisfies a discrete version of the divergence theorem: in the volume average, all the tendencies due to intercell fluxes within $D$ cancel out, leaving only the domain boundary fluxes.

The ocean model computes all of the terms in (1) at each hourly time step (Griffies et al. 2003) and saves out time averages of those terms as well as $T$, salinity $S$, and u. For the hourly diagnostics, we compute the total tendency $\partial_{t} T$ by directly differencing $T$ between the hourly model time steps. To compute $\partial_{t} T$ from longer time averages, we first linearly interpolate the timeaveraged (e.g., monthly mean) $T$ to the start and end of each averaging interval, and then difference across the interval.

The advection computed online by the ocean model's advection scheme, applied to its hourly $T$ and $\mathbf{u}$ fields, is referred to as the model's "total advection." To clarify the roles of fluctuations at different time scales, the total advection is then decomposed into three temporal components: monthly, submonthly (excluding subdaily), and subdaily.

The "monthly advection" component is computed by applying an offline finite-differencing method to the monthly-mean $T$ and $\mathbf{u}$ fields output by the model, as follows. The ocean model uses a staggered Arakawa B grid: $u$ and $v$ are aligned with $T$ in the vertical, but are set at the $T$-cell corners in the horizontal; and $w$ is aligned with $T$ in the horizontal, but is centered on the $T$-cell faces in the vertical. The time-averaged $T$ and u components are linearly interpolated from the model grid to the center of each cell face, and then used to compute both the advective flux at each face and the contribution of each flux to the cell's temperature tendency. Although this simple offline method differs from the ocean model's more sophisticated advective scheme, we verified that when applied to the temperature and velocity fields at each (hourly) time step, the offline method closely reproduces the actual instantaneous model-computed advection at scales larger than three oceanic grid cells (i.e., $3^{\circ}$ longitude, $1^{\circ}$ latitude). When averaging over large spatial domains such as the ECT, or over durations longer than a day, the approximate offline hourly advection is indistinguishable from the exact online hourly advection computed by the model.

The "submonthly advection" (excluding subdaily) component is defined by computing the advection offline using daily-mean $T$ and $\mathbf{u}$, and then subtracting the monthly advection described above. The "subdaily advection" component is defined by subtracting the advection computed offline using daily-mean $T$ and $\mathbf{u}$, from the total advection. This subdaily advection is found to contribute very little to the equatorial temperature budget, except above $40 \mathrm{~m}$ in the far eastern Pacific where it serves to weaken the strong thermal stratification (Fig. 10c).

By definition, the monthly, submonthly, and subdaily components sum exactly to the total advection computed online by the ocean model. 


\section{REFERENCES}

Alexander, M. A., J. D. Scott, and C. Deser, 2000: Processes that influence sea surface temperature and ocean mixed layer depth variability in a coupled model. J. Geophys. Res., 105, 16 823-16 842, https://doi.org/10.1029/2000JC900074.

Boucharel, J., A. Timmermann, A. Santoso, M. H. England, F.-F. Jin, and M. A. Balmaseda, 2015: A surface layer variance heat budget for ENSO. Geophys. Res. Lett., 42, 3529-3537, https:// doi.org/10.1002/2015GL063843.

Brainerd, K. E., and M. C. Gregg, 1995: Surface mixed and mixing layer depths. Deep-Sea Res. I, 42, 1521-1543, https://doi.org/ 10.1016/0967-0637(95)00068-H.

Capotondi, A., and Coauthors, 2015: Understanding ENSO diversity. Bull. Amer. Meteor. Soc., 96, 921-938, https://doi.org/ 10.1175/BAMS-D-13-00117.1.

Chen, C., M. A. Cane, A. T. Wittenberg, and D. Chen, 2017: ENSO in the CMIP5 simulations: Life cycles, diversity, and responses to climate change. J. Climate, 30, 775-801, https://doi.org/ 10.1175/JCLI-D-15-0901.1.

Choi, K.-Y., G. A. Vecchi, and A. T. Wittenberg, 2015: Nonlinear zonal wind response to ENSO in the CMIP5 models: Roles of the zonal and meridional shift of the ITCZ/SPCZ and the simulated climatological precipitation. J. Climate, 28, 8556-8573, https://doi.org/10.1175/ JCLI-D-15-0211.1.

Collins, M., and Coauthors, 2010: The impact of global warming on the tropical Pacific and El Niño. Nat. Geosci., 3, 391-397, https://doi.org/10.1038/ngeo868.

Compo, G. P., and Coauthors, 2011: The Twentieth Century Reanalysis Project. Quart. J. Roy. Meteor. Soc., 137, 1-28, https:// doi.org/10.1002/qj.776.

Cravatte, S., W. S. Kessler, N. Smith, and S. E. Wijffels, 2016: First report of TPOS 2010. Tech. Rep. GOOS-215, 200 pp., http:// tpos2020.org/first-report/.

de Boyer Montégut, C., G. Madec, A. S. Fischer, A. Lazar, and D. Iudicone, 2004: Mixed layer depth over the global ocean: An examination of profile data and a profile-based climatology. J. Geophys. Res., 109, C12003, https://doi.org/10.1029/ 2004JC002378.

Dee, D. P., and Coauthors, 2011: The ERA-Interim reanalysis: Configuration and performance of the data assimilation system. Quart. J. Roy. Meteor. Soc., 137, 553-597, https://doi.org/ 10.1002/qj.828.

DiNezio, P. N., and C. Deser, 2014: Nonlinear controls on the persistence of La Niña. J. Climate, 27, 7335-7355, https:// doi.org/10.1175/JCLI-D-14-00033.1.

—, B. P. Kirtman, A. C. Clement, S.-K. Lee, G. A. Vecchi, and A. Wittenberg, 2012: Mean climate controls on the simulated response of ENSO to increasing greenhouse gases. J. Climate, 25, 7399-7420, https://doi.org/10.1175/JCLI-D-11-00494.1.

Eyring, V., S. Bony, G. A. Meehl, C. A. Senior, B. Stevens, R. J. Stouffer, and K. E. Taylor, 2016: Overview of the Coupled Model Intercomparison Project phase 6 (CMIP6) experimental design and organization. Geosci. Model Dev., 9, 19371958, https://doi.org/10.5194/gmd-9-1937-2016.

Giese, B. S., and S. Ray, 2011: El Niño variability in simple ocean data assimilation (SODA), 1871-2008. J. Geophys. Res., 116, C02024, https://doi.org/10.1029/2010JC006695.

Graham, F., A. T. Wittenberg, J. N. Brown, S. J. Marsland, and N. J. Holbrook, 2017: Understanding the double peaked El Niño in coupled GCMs. Climate Dyn., 48, 2045-2063, https:// doi.org/10.1007/s00382-016-3189-1.
Griffies, S. M., 2012: Elements of the Modular Ocean Model (MOM): 2012 release. GFDL Ocean Group Tech. Rep. 7, 618 pp., http:// mom-ocean.org/web/docs/project/MOM5_elements.pdf.

—, M. J. Harrison, R. C. Pacanowski, and A. Rosati, 2003: A technical guide to MOM4. GFDL Ocean Group Tech. Rep 5, 295 pp.

—, and Coauthors, 2016: OMIP contribution to CMIP6: Experimental and diagnostic protocol for the physical component of the Ocean Model Intercomparison Project. Geosci. Model Dev., 9, 3231-3296, https://doi.org/10.5194/ gmd-9-3231-2016.

Huang, B., Y. Xue, D. Zhang, A. Kumar, and M. J. McPhaden, 2010: The NCEP GODAS ocean analysis of the tropical Pacific mixed layer heat budget on seasonal to interannual time scales. J. Climate, 23, 4901-4925, https://doi.org/10.1175/ 2010JCLI3373.1.

,,-- H. Wang, W. Wang, and A. Kumar, 2012: Mixed layer heat budget of the El Niño in NCEP Climate Forecast System. Climate Dyn., 39, 365-381, https://doi.org/10.1007/ s00382-011-1111-4.

Kara, A. B., P. A. Rochford, and H. E. Hurlburt, 2000: An optimal definition for ocean mixed layer depth. J. Geophys. Res., 105, 16 803-16 821, https://doi.org/10.1029/2000JC900072.

Kim, S.-B., I. Fukumori, and T. Lee, 2006: The closure of the ocean mixed layer temperature budget using level-coordinate model fields. J. Atmos. Oceanic Technol., 23, 840-853, https://doi.org/ 10.1175/JTECH1883.1.

_ T. Lee, and I. Fukumori, 2007: Mechanisms controlling the interannual variation of mixed layer temperature averaged over the Niño-3 region. J. Climate, 20, 3822-3843, https:// doi.org/10.1175/JCLI4206.1.

Large, W. G., J. C. McWilliams, and S. C. Doney, 1994: Oceanic vertical mixing: A review and a model with a nonlocal boundary layer parameterization. Rev. Geophys., 32, 363-403, https://doi.org/10.1029/94RG01872.

Lee, T., I. Fukumori, and B. Tang, 2004: Temperature advection: Internal versus external processes. J. Phys. Oceanogr., 34, 1936-1944, https://doi.org/10.1175/1520-0485(2004)034<1936: TAIVEP $>2.0 . \mathrm{CO} ; 2$.

Levitus, S., 1982: Climatological atlas of the world ocean. Prof. Pap. 13, U.S. Government Printing Office, 173 pp.

McPhaden, M. J., 2002: Mixed layer temperature balance on intraseasonal timescales in the equatorial Pacific Ocean. J. Climate, 15, 2632-2647, https://doi.org/10.1175/1520-0442(2002)015<2632: MLTBOI>2.0.CO;2.

Praveen Kumar, B., J. Vialard, M. Lengaigne, V. Murty, and M. McPhaden, 2012: TropFlux: Air-sea fluxes for the global tropical oceans-Description and evaluation. Climate Dyn., 38, 1521-1543, https://doi.org/10.1007/s00382-011-1115-0.

Qiu, B., and K. A. Kelly, 1993: Upper-ocean heat balance in the Kuroshio Extension region. J. Phys. Oceanogr., 23, 2027-2041, https://doi.org/10.1175/1520-0485(1993)023<2027:UOHBIT> 2.0.CO;2.

Qu, T., 2003: Mixed layer heat balance in the western North Pacific. J. Geophys. Res., 108, 3242, https://doi.org/10.1029/ 2002JC001536.

Ray, S., A. T. Wittenberg, S. M. Griffies, and F. Zeng, 2018: Understanding the equatorial Pacific cold tongue time-mean heat budget. Part II: Evaluation of the GFDL-FLOR coupled GCM. J. Climate, 31, 9987-10011, https://doi.org/10.1175/ JCLI-D-18-0153.1.

Rayner, N., D. E. Parker, E. Horton, C. Folland, L. Alexander, D. Rowell, E. Kent, and A. Kaplan, 2003: Global analyses 
of sea surface temperature, sea ice, and night marine air temperature since the late nineteenth century. J. Geophys. Res., 108, 4407, https://doi.org/10.1029/2002JD002670.

Smith, R., J. Dukowicz, and R. Malone, 1992: Parallel ocean general circulation modeling. Physica $D, 60,38-61$, https:// doi.org/10.1016/0167-2789(92)90225-C.

Swenson, M. S., and D. V. Hansen, 1999: Tropical Pacific Ocean mixed layer heat budget: The Pacific cold tongue. J. Phys. Oceanogr., 29, 69-81, https://doi.org/10.1175/1520-0485(1999) 029<0069:TPOMLH $>2.0$. CO;2.

Timmermann, A., and Coauthors, 2018: El Niño-Southern Oscillation complexity. Nature, 559, 535-545, https://doi.org/ 10.1038/s41586-018-0252-6.

Vecchi, G. A., and A. T. Wittenberg, 2010: El Niño and our future climate: Where do we stand? Wiley Interdiscip. Rev.: Climate Change, 1, 260-270, https://doi.org/10.1002/wcc.33.

_ , and Coauthors, 2014: On the seasonal forecasting of regional tropical cyclone activity. J. Climate, 27, 7994-8016, https:// doi.org/10.1175/JCLI-D-14-00158.1.

Vialard, J., C. Menkes, J.-P. Boulanger, P. Delecluse, E. Guilyardi, M. J. McPhaden, and G. Madec, 2001: A model study of oceanic mechanisms affecting equatorial Pacific sea surface temperature during the 1997-98 El Niño. J. Phys. Oceanogr., 31, 1649-1675, https://doi.org/10.1175/1520-0485(2001)031<1649: AMSOOM $>2.0 . \mathrm{CO} ; 2$.

Wittenberg, A. T., 2002: ENSO response to altered climates. Ph.D. thesis, Princeton University, $475 \mathrm{pp}$.

— , 2015: Low-frequency variations of ENSO. U.S. CLIVAR Variations, Vol. 13, US CLIVAR Project Office, Washington, D.C., 21-25.

— A. Rosati, N.-C. Lau, and J. J. Ploshay, 2006: GFDL's CM2 global coupled climate models. Part III: Tropical Pacific climate and ENSO. J. Climate, 19, 698-722, https://doi.org/ 10.1175/JCLI3631.1.

— , and Coauthors, 2018: Improved simulations of tropical Pacific annual-mean climate in the GFDL FLOR and HiFLOR coupled GCMs. J. Adv. Model. Earth Syst., in press.

Zebiak, S. E., and M. A. Cane, 1987: A model El Niño-Southern Oscillation. Mon. Wea. Rev., 115, 2262-2278, https://doi.org/ 10.1175/1520-0493(1987)115<2262:AMENO>2.0.CO;2.

Zheng, Y., G. N. Kiladis, T. Shinoda, E. J. Metzger, H. E. Hurlburt, J. Lin, and B. S. Giese, 2010: Upper-ocean processes under the stratus cloud deck in the southeast Pacific Ocean. J. Phys. Oceanogr., 40, 103-120, https://doi.org/10.1175/2009JPO4213.1. 